\title{
Discrete Sizing of Steel Frames Using Adaptive Dimensional Search Algorithm
}

\author{
Oğuzhan Hasançebi', Saeid Kazemzadeh Azad²* \\ ${ }^{1}$ Department of Civil Engineering, Faculty of Engineering, Middle East Technical University, Üniversiteler Mahallesi, \\ Dumlupınar Bulvarı, 06800 Çankaya, Ankara, Turkey \\ 2 Department of Civil Engineering, Faculty of Engineering, Atilim University, Kızılcaşar Mahallesi, 06836 Incek, Ankara, Turkey \\ * Corresponding author, e-mail: saeid.azad@atilim.edu.tr
}

Received: 26 July 2019, Accepted: 20 September 2019, Published online: 30 October 2019

\begin{abstract}
Adaptive dimensional search (ADS) algorithm is a recently proposed metaheuristic optimization technique for discrete structural optimization problems. In this study, discrete sizing optimization problem of steel frames is tackled using the ADS algorithm. An important feature of the algorithm is that it does not use any metaphor as an underlying principle for its implementation. Instead, the algorithm employs an efficient performance-oriented methodology at each iteration for convergence to the optimum or a near optimum solution. The performance of the ADS is investigated through optimum design of five real-size steel frame structures and the results are compared versus several contemporary metaheuristic techniques. The comparison of the obtained numerical results with those of available designs in the literature reveals the reliability and efficiency of the ADS in optimum design of steel frames.
\end{abstract}

\section{Keywords}

structural design, discrete optimization, steel frames, metaheuristic algorithms, adaptive dimensional search, sizing optimization

\section{Introduction}

In the last few decades, optimum design of engineering systems received considerable attention in the research community due to the globally increasing economic and environmental concerns. On the one hand, optimization provides the industry with an opportunity to produce more economical designs, and on the other hand, by reducing the material consumption as well as labor hours, alleviates the environmental problems such as carbon footprint of production and construction procedures. In general, optimum design of structural systems requires decision making on a set of design variables with respect to the strength and serviceability requirements imposed by a standard design code. Due to the wide range of applications of steel frames in the construction industry, many research studies addressed methodologies to enhance the design optimization procedure of steel frames so far [1]. Typically, in practical applications the frame members are selected from an available list of steel profiles. Therefore, commonly an optimization problem with discrete design variables is be solved in order to achieve an optimum or a near optimum final design. Indeed, development of numerous discrete optimization methodologies is basically due to the fact that the current computational technologies are not capable of performing an exhaustive search in the solution space by evaluation of all candidate solutions in a timely manner.

In the past decades, various research studies have been conducted on developing efficient design optimization techniques for structural engineering applications [2-9]. In fact, most of the recently proposed optimization algorithms for discrete sizing of steel frames belong to the class of stochastic search techniques or the so-called metaheuristics $[2,10,11]$. In general, metaheuristic techniques, such as genetic algorithms [12], particle swarm optimization [13], ant colony optimization [14, 15], etc., borrow their working principles from natural phenomena [16]; and follow non-deterministic search strategies for locating an optimum or a near optimum solution. The common methodology for development of metaheuristic based structural optimization techniques is to consider the neighborhood of promising candidate solutions found in each iteration to predict the search direction of the next iteration. Usually, a metaheuristic technique performs a global search in the early stages of the optimization, by exploring a wide area of the solution space, and gradually turns into a local 
search process in the last iterations to enhance the quality of the final solution. The popularity of metaheuristics structural optimization techniques can be attributed to their promising solutions, robust performances, independency to gradient information, and capability of handling both discrete and continuous design variables. The metaheuristic methods of structural optimization as well as their practical applications have been generally surveyed by Lamberti and Pappalettere [17].

For a more efficient search in the design space, adaptive metaheuristics refine their search strategies during the optimization process [18-20]. Recently, an adaptive dimensional search (ADS) technique was proposed by Hasançebi and Kazemzadeh Azad [21] for discrete sizing optimization of truss structures. In the ADS, the search dimensionality ratio (SDR) is adaptively updated, during the optimization process, to control the convergence rate of the algorithm. It was attempted to provide a balance between the exploration and exploitation characteristics of the ADS during its search in the design space based on the performance of the technique at each iteration. The efficiency of the ADS, in discrete truss optimization problems, is demonstrated in Hasançebi and Kazemzadeh Azad [21] compared to several contemporary metaheuristic algorithms. In addition to the efficiency of the ADS in discrete sizing optimization problems, another important feature of the algorithm is that it does not use any metaphor as an underlying principle for its implementation. Instead, the algorithm employs a simple, yet efficient performance-oriented methodology based on the update of the SDR parameter at each iteration for convergence to the optimum or a near optimum solution. This performance-oriented feature of the ADS makes it much easier for structural engineers to better understand the working principles of the technique for coding and implementation.

Considering the promising performance of the ADS in optimum design of truss structures, in the present study, the algorithm is reformulated for tackling discrete sizing optimization problems of real-size steel frames. The performance of the ADS is investigated through optimum design of five real-size steel frame structures, namely a 132-member unbraced space steel frame, a 325-member braced space steel frame, a 568-member unbraced space steel frame, a 744-member unbraced steel frame, and a 1860 -member braced steel frame. The results obtained by the ADS demonstrate that the algorithm is capable of locating promising solutions with an acceptable level of conformity to those of other contemporary discrete sizing optimization techniques.
The remaining parts of the study are organized as follows. Section 2 describes the discrete sizing optimization problem of steel frames according to AISC-ASD [22]. In Section 3 provides a detailed description of computational steps involved in the ADS algorithm are overviewed. Section 4 presents the performance evaluation of the ADS algorithm using real-size steel frame instances. Section 5 provides a brief conclusion of the study.

\section{Practical design optimization of steel frames}

In real-world applications the steel frame members are usually selected from a set of available steel sections, which yields a discrete optimization problem. For a steel frame consisting of $N_{m}$ members that are collected in $N_{d}$ member groups, the design optimization problem according to AISC-ASD [22] can be formulated as follows.

The optimization objective is to find a vector of integer values I (Eq. (1)) representing the sequence numbers of steel sections assigned to $N_{d}$ member groups,

$$
\mathbf{I}^{T}=\left[I_{1}, I_{2}, \ldots, I_{N_{d}}\right],
$$

to minimize the weight $(W)$ of the frame

$W=\sum_{i=1}^{N_{d}} \rho_{i} A_{i} \sum_{j=1}^{N_{t}} L_{j}$

where $A_{i}$ and $\rho_{i}$ are the length and unit weight of the steel section adopted for member group $i$, respectively, $N_{t}$ is the total number of members in group $i$, and $L_{j}$ is the length of the member $j$ which belongs to group $i$.

The frame members subjected to a combination of axial compression and flexural stress should be sized to satisfy the following stress constraints (Eqs. (3)-(5)):

if $\frac{f_{a}}{F_{a}}>0.15 ;\left[\frac{f_{a}}{F_{a}}+\frac{C_{m x} f_{b x}}{\left(1-\frac{f_{a}}{F_{e x}^{\prime}}\right) F_{b x}}+\frac{C_{m y} f_{b y}}{\left(1-\frac{f_{a}}{F_{e y}^{\prime}}\right) F_{b y}}\right]-1.0 \leq 0$

$\left[\frac{f_{a}}{0.60 F_{y}}+\frac{f_{b x}}{F_{b x}}+\frac{f_{b y}}{F_{b y}}\right]-1.0 \leq 0$,

if $\frac{f_{a}}{F_{a}} \leq 0.15 ; \quad\left[\frac{f_{a}}{F_{a}}+\frac{f_{b x}}{F_{b x}}+\frac{f_{b y}}{F_{b y}}\right]-1.0 \leq 0$.

If the flexural member is under tension, then the formula given in Eq. (6) is used instead:

$$
\left[\frac{f_{a}}{0.60 F_{y}}+\frac{f_{b x}}{F_{b x}}+\frac{f_{b y}}{F_{b y}}\right]-1.0 \leq 0 \text {. }
$$


In Eqs. (3)-(6), $F_{y}$ is the material yield stress, and $f_{a}=(P / A)$ represents the calculated axial stress, where $A$ is the cross-sectional area of the member. The calculated flexural stresses due to bending of the member about its major (x) and minor (y) principal axes are denoted by $f_{b x}$ and $f_{b y}$, respectively. $F_{e x}^{\prime}$ and $F_{e y}^{\prime}$ denote the Euler stresses about principal axes of the member that are divided by a factory of safety of 23/12. $F_{a}$ stands for the allowable axial stress under axial compression force alone, and is calculated depending on elastic or inelastic bucking failure mode of the member using Formulas 1.5-1 and 1.5-2 given in AISC-ASD [22]. The allowable bending compressive stresses about major and minor axes are designated by $F_{b x}$ and $F_{b y}$, which are computed using the Formulas 1.5-6a or 1.5-6b and 1.5-7 given in AISC-ASD [22]. It is important to note that while calculating allowable bending stresses, a newer formulation (Eq. (7)) of moment gradient coefficient $c_{b}$ given in ANSI/AISC 360-05 [23] is employed in the study to account for the effect of moment gradient on lateral torsional buckling resistance of the elements,

$c_{b}=\frac{12.5 M_{\text {max }}}{2.5 M_{\text {max }}+3 M_{A}+4 M_{B}+3 M_{C}} R_{m} \leq 3.0$,

where $M_{\max }, M_{A}, M_{B}$ and $M_{C}$ are the absolute values of maximum, quarter-point, midpoint, and three-quarter point moments along the unbraced length of the member, respectively, and $R_{m}$ is a coefficient which is equal to 1.0 for doubly symmetric sections. $C_{m x}$ and $C_{m v}$ are the reduction factors, introduced to counterbalance overestimation of the second-order moments by the amplification factor $\left(1-f_{a} / F_{e}^{\prime}\right)$. For unbraced frame members, they are taken as 0.85 . For braced frame members without transverse loading between their ends, they are computed from $C_{m}=0.6-0.4\left(M_{1} / M_{2}\right)$, where $M_{1} / M_{2}$ is the ratio of smaller end moment to the larger end moment. For braced frame members having transverse loading between their ends, they are determined from the formula $C_{m}=1+\psi\left(f_{a} / F_{e}^{\prime}\right)$ based on a rational approximate analysis outlined in AISC-ASD [22] Commentary-H1, where $\psi$ is a parameter that considers maximum deflection and maximum moment in the member.

For the computation of allowable compression and Euler stresses, the effective length factors $(K)$ are required. For beam and bracing members, $K$ is taken equal to unity. For column members, alignment charts furnished in AISCASD [22] can be utilized. In the present work, however, the effective length factors of columns in braced and unbraced steel frames are computed from the approximate formulas (Eqs. (8), (9)) developed by Dumonteil [24], which are accurate to within about -1.0 and $+2.0 \%$ of the exact results [25]:

For unbraced members:

$K=\sqrt{\frac{1.6 G_{A} G_{B}+4\left(G_{A}+G_{B}\right)+7.5}{G_{A}+G_{B}+7.5}}$.

For braced members:

$K=\frac{3 G_{A} G_{B}+1.4\left(G_{A}+G_{B}\right)+0.64}{3 G_{A} G_{B}+2.0\left(G_{A}+G_{B}\right)+1.28}$,

where $G_{A}$ and $G_{B}$ refer to stiffness ratio or relative stiffness of a column at its two ends.

It is also required that the computed shear stresses $\left(f_{v}\right)$ in members are smaller than the allowable shear stresses $\left(F_{v}\right)$, as formulated in Eq. (10).

$f_{v} \leq F_{v}=0.40 C_{v} F_{y}$

In Eq. (10), $C_{v}$ is referred to as web shear coefficient. It is taken equal to $C_{v}=1.0$ for rolled W-shaped members with $h / t_{w} \leq 2.24 E / F_{v}$, where $\mathrm{h}$ is the clear distance between flanges, $E$ is the elasticity modulus and $t_{w}$ is the thickness of web. For all other symmetric shapes, $C_{v}$ is calculated from Formulas G2-3, G2-4 and G2-5 in ANSI/ AISC 360-05 [23].

Apart from stress constraints, slenderness limitations are also imposed on all members such that maximum slenderness ratio $(\lambda=K L / r)$ is limited to 300 and 200 for tension and compression members, respectively. The displacement constraints are imposed such that the maximum lateral displacements are restricted to be less than $\mathrm{H} / 400$, and upper limit of story drift is set to be $\mathrm{h} / 400$, where $\mathrm{H}$ is the total height of the frame building and $\mathrm{h}$ is the height of a story.

Finally, we consider geometric constraints between beams and columns framing into each other at a common joint for practicality of an optimum solution generated. For the two beams B1 and B2 and the column shown in Fig. 1, one can write the following geometric constraints:

$$
\begin{aligned}
& \frac{b_{f b}}{b_{f c}}-1.0 \leq 0, \\
& \frac{b_{f b}^{\prime}}{\left(d_{c}-2 t_{f}\right)}-1.0 \leq 0,
\end{aligned}
$$

where $b_{f b}, b_{f b}^{\prime}$ and $b_{f c}$ are the flange width of the beam $\mathrm{B} 1$, the beam B2 and the column, respectively, $d_{c}$ is the depth of the column, and $t_{f}$ is the flange width of the column. Eq. (11) ensures that the flange width of the beam 


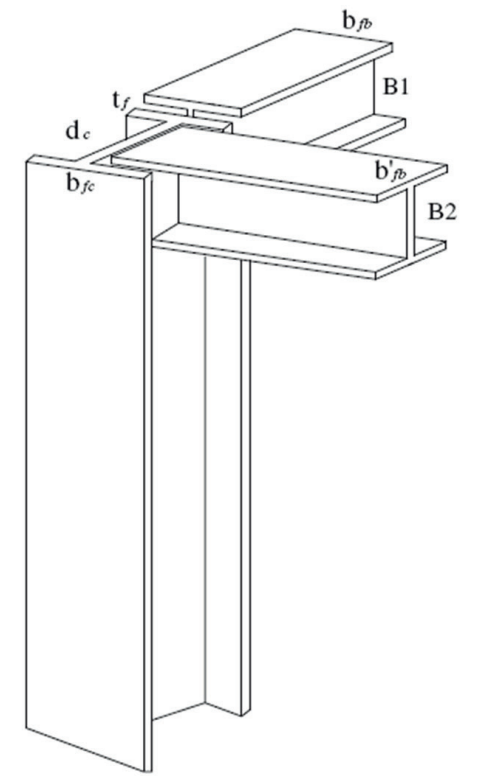

Fig. 1 Beam-column geometric constraints

B1 remains smaller than that of the column. On the other hand, Eq. (12) enables that flange width of the beam B2 remains smaller than clear distance between the flanges of the column $\left(d_{c}-2 t_{f}\right)$.

\section{Adaptive Dimensional Search (ADS) technique}

The adaptive dimensional search (ADS) [21] is a recently proposed population-based metaheuristic optimization algorithm where only the best solution of the previous population is used to generate $\mu$ number of candidate solutions in the current population. This type of selection scheme is commonly referred to as $(1+\mu)$-type selection in the literature and has been formerly employed by some variants of evolution strategies [26] as well as big bang-big crunch method [27].

The robustness of the ADS method lies in the idea of updating search dimensional rate (SDR) parameter online during the search to achieve a satisfactory tradeoff between exploration and exploitation features of the search process. In general, SDR can be defined as the percentage of the design variables that are perturbed probabilistically while generating a candidate solution from the current (best) design, Eq. (13)

$$
\mathrm{SDR}=\frac{N_{p}}{N_{d}},
$$

where $N_{p}$ is the number of design variables perturbed to generate a new solution and $N_{d}$ is the total number of design variables. The need for changing not all, but a percentage of design variables in discrete structural optimization problems stems from the sensitivity of structural response to sizing variables in such problems. That is to say, even small changes in a few variables may yield a candidate solution that will have a completely different structural behavior than the design from which it is originated. The role of SDR parameter is to adjust explorative and exploitative search features of the ADS algorithm, which is explained in detail in the following. The steps in the implementation of the ADS can now be outlined as follows.

Step 1. Initial population: An initial population consisting of a predefined number of candidate solutions is generated randomly. This step is performed once.

Step 2. Evaluation: The population is evaluated, where structural analyses of all candidate solutions are performed with the set of steel sections selected for design variables, and force and deformation responses are obtained under the loads. The objective function values of the feasible solutions that satisfy all problem constraints are directly calculated from Eq. (2). However, infeasible solutions that violate some of the problem constraints are penalized using an external penalty function approach, and their objective function values are calculated according to Eq. (14).

$$
\varphi=W\left[1+p\left(\sum_{i} c_{i}\right)\right]
$$

In Eq. (14), $\varphi$ is the constrained objective function value, $c_{i}$ is the $i$-th problem constraint and $p$ is the penalty coefficient used to tune the intensity of penalization as a whole. Step 3. Setting ADS parameter: For the initial population, the SDR parameter is set to its initial value $\operatorname{SDR}(0)$, which is taken as 0.25 for all the numerical examples discussed here. For other populations it is generated in the course of optimization using Eq. (15) depending on whether or not the best solution has been improved in the previous iteration $(t-1)$ of the algorithm.

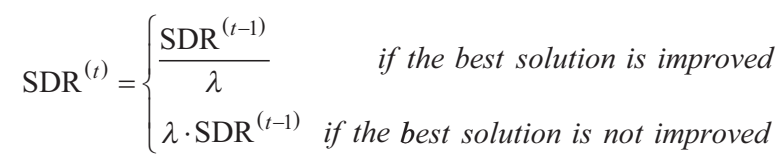

According to Eq. (15) if the best solution found so far is improved in the previous iteration $t-1$, then the value of SDR is increased in the current iteration $t$ by dividing its value by a factor $\lambda<1.0$, otherwise SDR is decreased by multiplying its value by $\lambda$. The factor $\lambda$ is referred to as search dimensional adaptation parameter (taken as 0.98 in this study), and determines the rate of adaptation towards the new value of SDR parameter. The high values of SDR motivate a more explorative search by enabling 
moves in the search space through the change of many design variables at a time, resulting in large, yet relatively unfettered step sizes. On the other hand, the low values of SDR lead to a more explorative search by facilitating small, yet more conservative moves in the design space. The rationale behind Eq. (15) is to promote a more explorative search, if any of the moves in the previous iteration leads to an improved solution. This way the search dimension is increased, and the algorithm is encouraged to discover new solutions in an extended region of the search space. On the other hand, if the previous iteration leads to no improvement, diverse search is somewhat limited, and the algorithm is biased towards sampling by small and judicious moves around the current design. This way the SDR parameter is updated at each iteration to benefit from a more explorative or exploitative search alternately for the most efficient optimization process. It is recommended to define an upper and a lower bound for the variation of SDR, which are set to 0.5 and $1 / N_{d}$, respectively where $N_{d}$ refers to the total number of design variables of the optimization problem.

Step 4. New population: A new population is formed where candidate solutions are generated from the best design obtained so far using Eq. (16).

$I_{i}^{\text {new }}=\left\{\begin{array}{cl}I_{i}^{c} & \text { if } r_{i}>\mathrm{SDR} \\ I_{i}^{c}+\text { round }\left[N_{i}(0,1)\left(\sqrt{\left(I_{i}^{\max }-I_{i}^{\min }\right)}-\left(\sqrt{\left(I_{i}^{\max }-I_{i}^{\min }\right)}-1\right) \frac{t}{\max _{-} t}\right)\right] & \text { if } r_{i} \leq \mathrm{SDR}\end{array}\right.$

In Eq. (16) $I_{i}^{c}$ is the value of $i$-th design variable in the best design obtained so far, $I_{i}^{\text {new }}$ is the value of the corresponding design variable in a candidate solution, and $r_{i}$ is a uniform random number sampled between 0 and 1 for $i$-th design variable. Accordingly, while generating a candidate solution, a random number $r_{i}$ is sampled anew for each design variable $i$. If it is greater than SDR, then the value of the $i$-th design variable in a candidate solution is directly copied from the best design, i.e., $I_{i}^{\text {new }}=I_{i}^{c}$. Otherwise $\left(r_{i} \leq \mathrm{SDR}\right)$; a new value is assigned to the candidate solution for the respective design variable between its lower $\left(I_{i}^{\min }\right)$ and upper $\left(I_{i}^{\max }\right)$ bounds using the lower expression in Eq. (16). In this expression $N_{i}(0,1)$ is a random number generated anew for each $i$-th design variable according to a standard normal distribution with mean zero and standard deviation one, $t$ is the current iteration number, and max_t is the maximum number of iterations to be performed during the course of optimization. In case a selected design variable is not changed, a perturbation of +1 or -1 is implemented (with equal probability) to ensure a minimum change in the considered variable. It should be noted that Eq. (16) enables a change of different set of design variables for each candidate solution under the same SDR value.

Step 5. Elitism: The best solution found so far is kept in a separate place and involved in the population if any of the candidate solutions in the current population does not outperform it. It should be noted that the best design refers to either a feasible or infeasible solution with the minimum objective function value obtained so far in accordance with Eq. (2) or (14). In fact, this is the design which is used to originate candidate solutions using Eq. (16). Apart from the best design, the algorithm also stores the feasible best design, which corresponds to the best design achieved by the algorithm with strictly no constraint violation during the optimization process.

Step 6. Stagnation-control: The algorithm is checked against stagnation. Three alternative stagnation-control strategies were proposed in Hasançebi and Kazemzadeh Azad [21] for the ADS algorithm to protect it against entrapment in local optima, and thus to perform a more efficient search in the solution space. The details of different stagnation-control strategies can be found in Hasançebi and Kazemzadeh Azad [21] and are not repeated here.

Step 7. Termination: The algorithm proceeds back to Step 2 until a stopping criterion is met. This can be considered as a maximum number of iterations or no improvement of the best solution found over a certain number of iterations.

\section{Design examples}

In Section 4, performance evaluation of the ADS algorithm is carried out using a test set of five practical frame optimization problems. The objective in these test instances is to evaluate the performance of the ADS algorithm against several robust contemporary metaheuristics. The parameters of ADS algorithm are selected as follows. The initial value of penalty coefficient $p$ is set to 1.0 , and a population size of 50 is employed for all the examples. The annealing strategy [21] is employed for stagnation-control of the ADS algorithm, for which a limited non-improving move is permitted when a stagnation state is detected in the course of optimization.

\subsection{Example 1: 132-member unbraced steel frame}

The first test example shown in Fig. 2 is an unbraced space steel frame composed of 70 joints and 132 members which are grouped into 30 independent sizing variables 




(a)

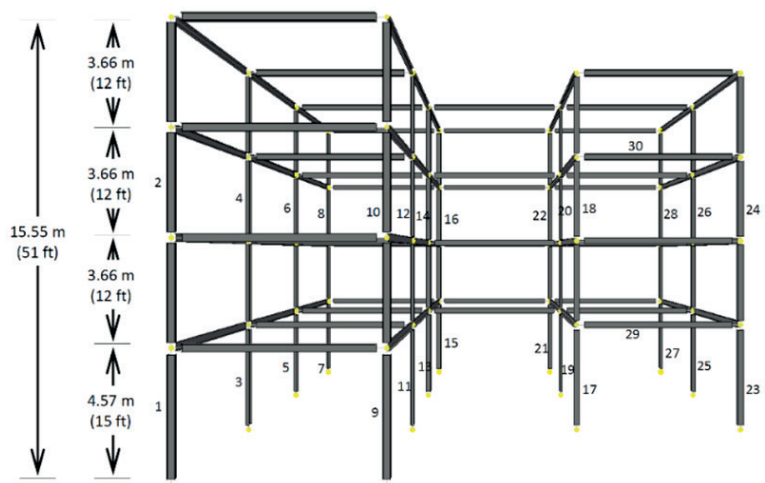

(b)

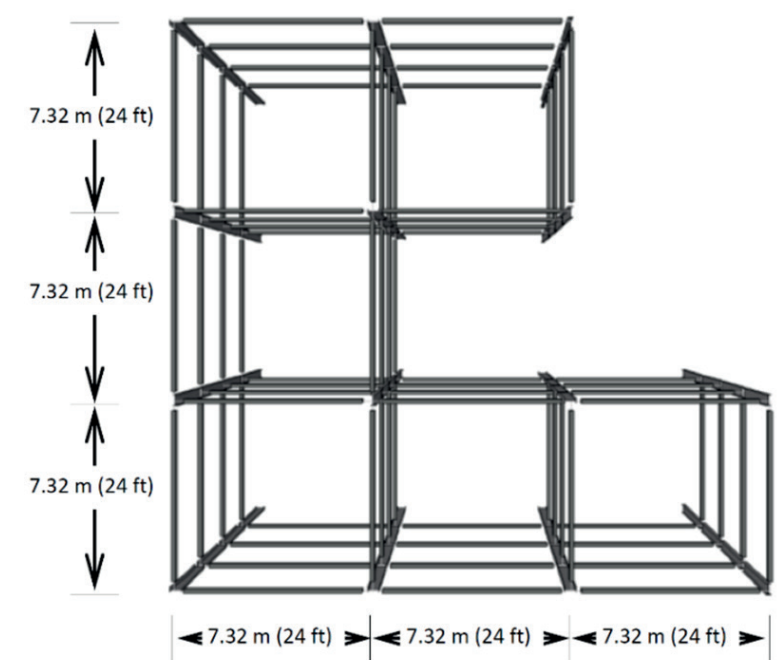

(c)

Fig. 2 132-member steel frame: (a) 3D view, (b) front view, (c) top view

(Fig. 2(b)) to satisfy practical fabrication requirements. This design optimization example has been already studied by Hasançebi et al. [28] as well as Hasançebi and Kazemzadeh Azad [29] using different optimization algorithms. Here, the columns are chosen from the complete W-shape profile list of 297 ready sections, whereas a discrete set of 171 economical sections, selected from $\mathrm{W}$-shape profile list based on cross sectional area and moment of inertia properties, is used to size the beam members. Moreover, both gravity and lateral loads are considered for designing the structure. Gravity loads $(G)$ consisting dead, live and snow loads are computed according to ASCE 7-05 [30] based on the following design values: a design dead load of $60.13 \mathrm{lb} / \mathrm{ft}^{2}\left(2.88 \mathrm{kN} / \mathrm{m}^{2}\right)$, a design live load of $50 \mathrm{lb} / \mathrm{ft}^{2}\left(2.39 \mathrm{kN} / \mathrm{m}^{2}\right)$, and a ground snow load of $25 \mathrm{lb} / \mathrm{ft}^{2}\left(1.20 \mathrm{kN} / \mathrm{m}^{2}\right)$. This yields the uniformly distributed loads on the outer and inner beams of the roof and floors given in Table 1. As for the lateral forces, earthquake loads (E) are considered. These loads are calculated using the equivalent lateral force procedure outlined in ASCE 7-05 [30], resulting in the values given in Table 1 that are applied at the center of gravity of each story as joint loads. Gravity (G) and earthquake (E) loads are combined under two loading conditions for the frame: (i) $1.0 \mathrm{G}+1.0 \mathrm{E}$ (in $\mathrm{x}$-direction), and (ii) $1.0 \mathrm{G}+1.0 \mathrm{E}$ (in y-direction). The combined stress, stability and geometric constraints are imposed as already explained. The joint displacements in $x$ and $y$ directions are limited to 1.53 in $(3.59 \mathrm{~cm})$ which is obtained as height of frame/400. Furthermore, story drift constraints are applied to each story of the steel frame which is equal to height of each story/400.

Discrete sizing of the 132-member steel frame is performed using the ADS algorithm and the results obtained are compared to the previously reported designs using different metaheuristic techniques in Hasançebi et al. [28], and Hasançebi and Kazemzadeh Azad [29]; namely improved simulated annealing (ISA), tabu search (TS), harmony search (HS), big bang-big crunch (BB-BC), exponential BB-BC (EBB-BC), and modified BB-BC (MBB-BC) algorithms. As presented in Table 2 the ADS algorithm produces a design weight of $125240.17 \mathrm{lb}$ $(56807.99 \mathrm{~kg})$ for the 132 -member steel frame which is the best solution of this problem reported so far. Relatively higher design weights have been obtained for the frame with other metaheuristic algorithms; namely $138874.67 \mathrm{lb}$ $(62993.55 \mathrm{~kg})$ by ISA, $142710.96 \mathrm{lb}(64733.69 \mathrm{~kg})$ by TS, $143135.29 \mathrm{lb}(64926.17 \mathrm{~kg})$ by HS, $192834.39 \mathrm{lb}$ $(87468.21 \mathrm{~kg})$ by BB-BC, $134050.55 \mathrm{lb}(60804.31 \mathrm{~kg})$ by EBB-BC, and $139016.28 \mathrm{lb}(63056.72 \mathrm{~kg})$ by MBB-BC. The convergence history for the best feasible design found in the course of optimization using the ADS algorithm is depicted Fig. 3. 
Table 1 The gravity and lateral loading on 132-member steel frame

\begin{tabular}{|c|c|c|c|c|}
\hline \multicolumn{5}{|c|}{ Gravity Loads } \\
\hline \multirow[t]{3}{*}{ Beam Type } & \multicolumn{4}{|c|}{ Uniformly Distributed Load } \\
\hline & \multicolumn{2}{|c|}{ Outer Span Beams } & \multicolumn{2}{|c|}{ Inner Span Beams } \\
\hline & $(\mathrm{lb} / \mathrm{ft})$ & $(\mathrm{kN} / \mathrm{m})$ & $(\mathrm{lb} / \mathrm{ft})$ & $(\mathrm{kN} / \mathrm{m})$ \\
\hline Roof beams (Dead + Snow Loads) & 1011.74 & 14.77 & 1193.84 & 17.42 \\
\hline Floor beams (Dead + Live Loads) & 1468.40 & 21.49 & 1732.70 & 25.29 \\
\hline \multicolumn{5}{|c|}{ Lateral Loads } \\
\hline \multirow[t]{2}{*}{ Floor Number } & \multicolumn{4}{|c|}{ Earthquake Design Load } \\
\hline & \multicolumn{2}{|c|}{ (kips) } & \multicolumn{2}{|c|}{$(\mathrm{kN})$} \\
\hline 1 & \multicolumn{2}{|c|}{6.57} & \multicolumn{2}{|c|}{29.23} \\
\hline 2 & \multicolumn{2}{|c|}{12.43} & \multicolumn{2}{|c|}{55.28} \\
\hline 3 & \multicolumn{2}{|c|}{18.52} & \multicolumn{2}{|c|}{82.35} \\
\hline 4 & \multicolumn{2}{|c|}{24.76} & \multicolumn{2}{|c|}{110.15} \\
\hline
\end{tabular}

Table 2 Comparison of results for 132-member steel frame

\begin{tabular}{|c|c|c|c|c|c|c|c|}
\hline Member Group & ISA & $\mathrm{TS}$ & HS & BB-BC & EBB-BC & MBB-BC & ADS \\
\hline 1 & W8X35 & W8X31 & W14X53 & W24X176 & W10X33 & W12X58 & W8X31 \\
\hline 2 & W18X86 & W12X65 & $\mathrm{W} 12 \mathrm{X} 120$ & W21X132 & W12X79 & W14X109 & W21X101 \\
\hline 3 & W12X79 & W27X129 & W30X48 & W27X336 & W40X167 & W10X100 & W24X104 \\
\hline 4 & W18X65 & W8X58 & W16X77 & W24X279 & W12X65 & W10X54 & W12X65 \\
\hline 5 & W12X65 & W12X79 & W18X119 & W14X193 & $\mathrm{W} 14 \mathrm{X} 120$ & W12X96 & W24X104 \\
\hline 6 & W27X161 & W12X106 & W24X104 & W14X109 & W14X109 & W14X90 & W21X101 \\
\hline 7 & W24X117 & W18X97 & W30X148 & W12X87 & W14X99 & W36X182 & W21X101 \\
\hline 8 & W10X54 & W8X58 & W10X68 & W27X94 & W14X90 & W12X65 & W21X68 \\
\hline 9 & W18X86 & W12X72 & W18X158 & W30X292 & $\mathrm{W} 10 \mathrm{X} 100$ & W18X130 & W12X72 \\
\hline 10 & W12X96 & W14X90 & $\mathrm{W} 12 \mathrm{X} 120$ & W18X283 & W12X106 & W14X90 & W33X130 \\
\hline 11 & W10X60 & W36X135 & $\mathrm{W} 36 \times 150$ & W10X49 & W33X152 & W12X58 & W21X68 \\
\hline 12 & W10X49 & W10X49 & W16X67 & W21X62 & W12X53 & W30X99 & W10X49 \\
\hline 13 & W12X87 & W12X96 & W10X112 & W18X311 & W14X90 & W44X224 & W14X90 \\
\hline 14 & W12X50 & W10X49 & W24X117 & W33X141 & W36X160 & W40X192 & W24X68 \\
\hline 15 & W24X55 & W24X55 & W18X40 & W18X40 & W18X40 & W16X40 & W21X44 \\
\hline 16 & W24X55 & W10X33 & W14X61 & $\mathrm{W} 12 \mathrm{X} 210$ & W12X53 & W8X35 & W8X24 \\
\hline 17 & W12X58 & W18X76 & W12X65 & W16X67 & W21X111 & W12X65 & W14X109 \\
\hline 18 & W12X67 & W21X83 & W18X119 & W12X65 & W12X65 & W12X96 & W12X65 \\
\hline 19 & $\mathrm{~W} 12 \mathrm{X} 40$ & W8X40 & W14X82 & W14X211 & W14X43 & W12X65 & W14X43 \\
\hline 20 & W10X49 & W14X61 & W18X86 & W14X211 & W10X60 & W12X65 & W16X67 \\
\hline 21 & $\mathrm{~W} 12 \mathrm{X} 72$ & W18X76 & W14X90 & W40X277 & W12X106 & W12X72 & W10X77 \\
\hline 22 & W12X79 & W12X72 & W18X97 & W33X141 & W10X88 & W12X72 & W12X72 \\
\hline 23 & W8X48 & W12X40 & W21X73 & W12X65 & W8X48 & W14X43 & W10X49 \\
\hline 24 & W24X68 & W24X76 & W12X87 & W30X326 & W27X84 & W18X119 & W12X79 \\
\hline 25 & W14X61 & W10X77 & W18X71 & W12X72 & W14X61 & W12X152 & W10X54 \\
\hline 26 & W21X50 & W16X50 & W27X102 & W8X28 & W10X39 & W12X53 & W12X58 \\
\hline 27 & W8X40 & W10X49 & W8X48 & W30X124 & W12X40 & W12X45 & W10X39 \\
\hline 28 & W8X67 & W14X61 & W24X117 & W24X94 & W18X76 & W12X72 & W24X117 \\
\hline 29 & W10X39 & W18X97 & W18X97 & W16X89 & W24X68 & W12X58 & W12X65 \\
\hline 30 & W21X44 & W16X45 & W16X40 & W21X44 & W18X40 & W16X40 & W18X35 \\
\hline Weight, lb (kg) & $\begin{array}{l}138874.67 \\
(62993.55)\end{array}$ & $\begin{array}{r}142710.96 \\
(64733.69)\end{array}$ & $\begin{array}{l}143135.29 \\
(64926.17)\end{array}$ & $\begin{array}{l}192834.39 \\
(87468.21)\end{array}$ & $\begin{array}{l}134050.55 \\
(60804.31)\end{array}$ & $\begin{array}{l}139016.28 \\
(63056.72)\end{array}$ & $\begin{array}{l}125240.17 \\
(56807.99)\end{array}$ \\
\hline
\end{tabular}




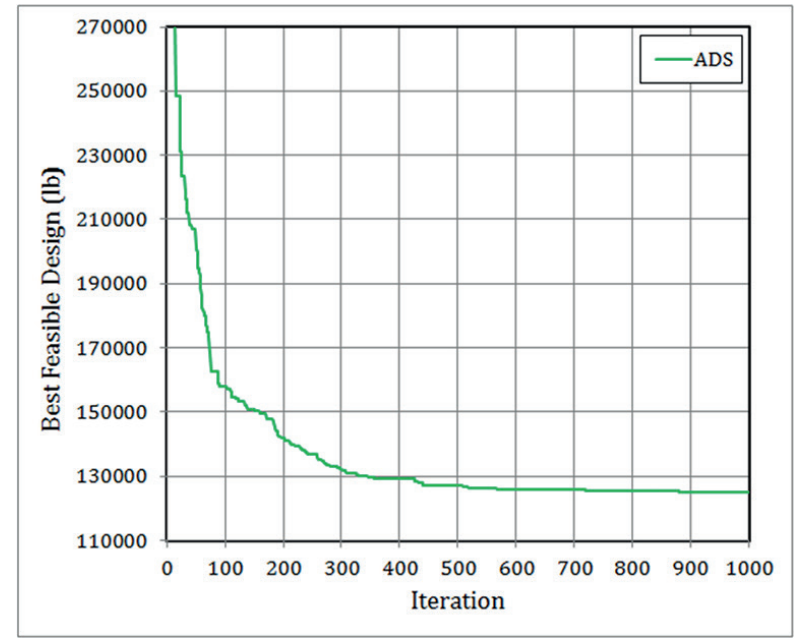

Fig. 3 Optimization history for 132-member steel frame using ADS

\subsection{Example 2: 325-member braced steel frame}

The space steel frame depicted in Fig. 4 is selected as the second design example for performance evaluation of the ADS algorithm. This instance has been formerly investigated in Hasançebi et al. [31]. The frame is braced with $\mathrm{K}$-type bracing in the first and last bays along the $\mathrm{x}$-direction and with X-type bracing system along y-direction. The 325 members of the frame are collected in 20 member groups as shown in Fig. 4(e). For this test example, gravity loads on the beams of roof and floors are tabulated in Table 3. As for lateral forces, earthquake loads (E) are computed based on the equivalent lateral force procedure outlined in ASCE 7-05 [30], resulting in point loads applied at the center of gravity of each respective story, as follows: 4.72 kips $(20.99 \mathrm{kN})$ at the 1 st story, 8.96 kips $(39.87 \mathrm{kN})$ at the 2nd story, 13.49 kips $(59.99 \mathrm{kN})$ at the 3rd story, 18.22 kips $(81.04 \mathrm{kN})$ at the 4th story, and $23.11 \mathrm{kips}(102.81 \mathrm{kN})$ at the 5 th story. The gravity and lateral loads are combined under two loading conditions for the frame: (i) $1.0 \mathrm{G}+1.0 \mathrm{E}$ (in $\mathrm{x}$-direction), and (ii) $1.0 \mathrm{G}+1.0 \mathrm{E}$ (in $\mathrm{y}$-direction). As already explained, the combined stress, stability, displacement and geometric constraints are imposed according to the provisions of AISC-ASD [22].

Optimization of the 325 -member braced steel frame is performed using the ADS algorithm and the results obtained as well as sectional designations for member groups are presented and compared to the results of other metaheuristics reported in Hasançebi et al. [31]. As can be seen from Table 4 the ADS algorithm locates the minimum weight as $128320.45 \mathrm{lb}(58205.177 \mathrm{~kg})$, which is the lightest of all the final designs. For this test example, relatively higher design

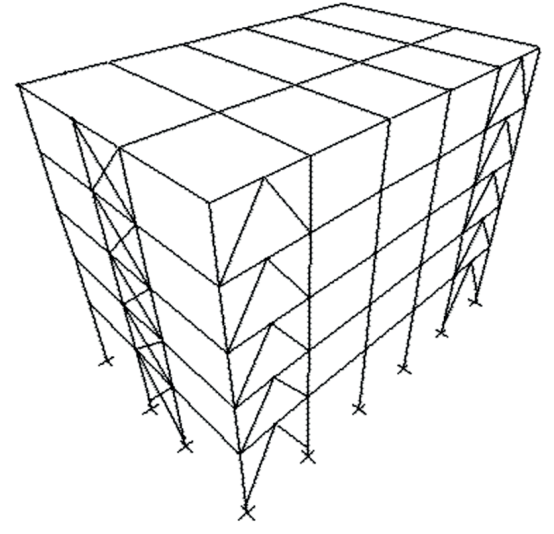

(a)

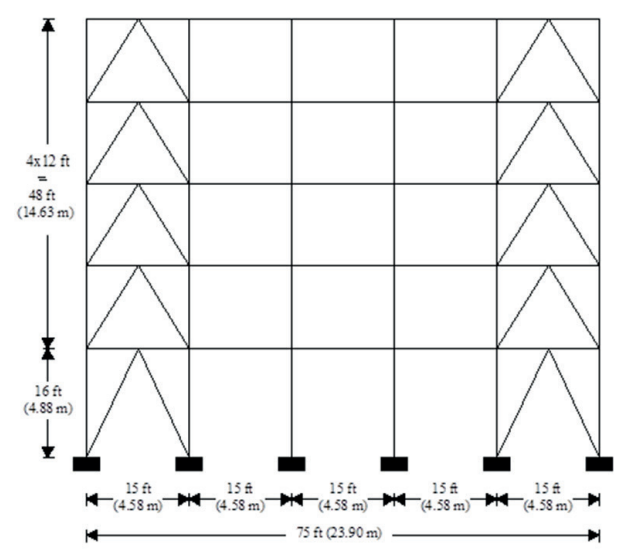

(b)

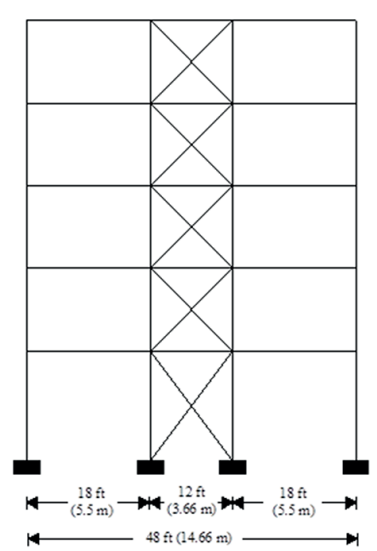

(c)

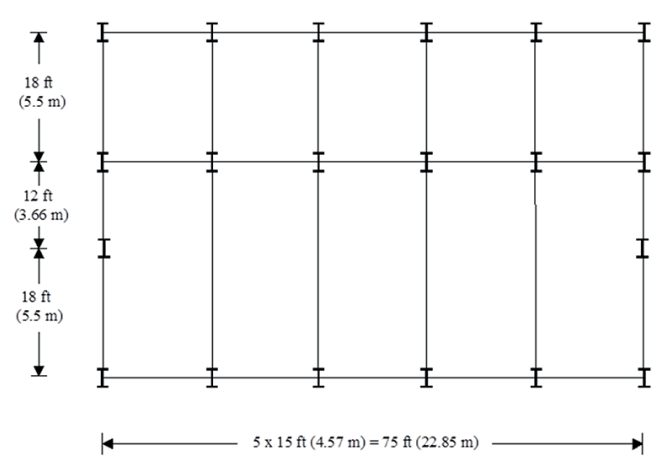

(d)

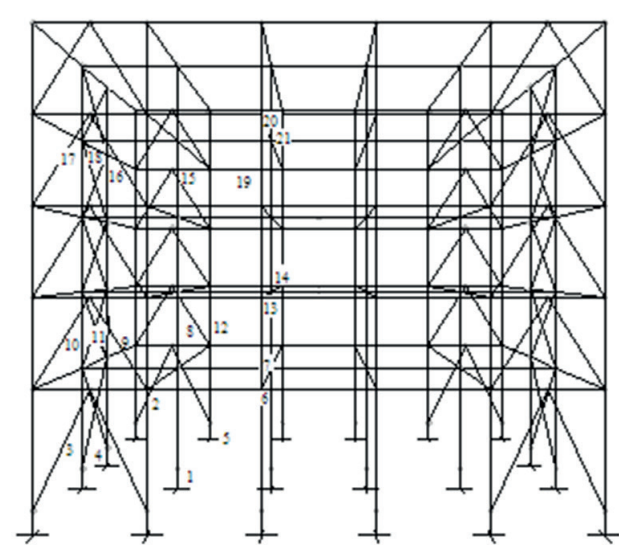

(e)

Fig. 4 325-member braced steel frame: (a) 3D view, (b) front view, (c) side view, (d) plan view, (e) member grouping 
Table 3 Gravity loading on the beams of 325-member braced steel frame

\begin{tabular}{|c|c|c|c|}
\hline \multirow{2}{*}{ Story } & \multirow{2}{*}{ Beams } & \multicolumn{2}{|c|}{ Uniformly Distributed Load } \\
\hline & & $(\mathrm{lb} / \mathrm{ft})$ & $(\mathrm{kN} / \mathrm{m})$ \\
\hline \multicolumn{4}{|c|}{ Beams along } \\
\hline \\
\hline \multirow{4}{*}{ Roof } & A1-B1, A6-B6 & 521.67 & 7.61 \\
\hline & $\begin{array}{l}\text { A2-B2, A3-B3, } \\
\text { A4-B4, A5-B5 }\end{array}$ & 1043.34 & 15.23 \\
\hline & B1-C1, B6-C6 & 437.36 & 6.38 \\
\hline & $\begin{array}{l}\mathrm{B} 2-\mathrm{C} 2, \mathrm{~B} 3-\mathrm{C} 3, \\
\mathrm{~B} 4-\mathrm{C} 4, \mathrm{~B} 5-\mathrm{C} 5\end{array}$ & 874.72 & 12.77 \\
\hline \multirow{4}{*}{ Floor } & A1-B1, A6-B6 & 757.14 & 11.05 \\
\hline & $\begin{array}{l}\text { A2-B2, A3-B3, } \\
\text { A4-B4, A5-B5 }\end{array}$ & 1514.28 & 22.10 \\
\hline & B1-C1, B6-C6 & 634.99 & 9.27 \\
\hline & $\begin{array}{l}\mathrm{B} 2-\mathrm{C} 2, \mathrm{~B} 3-\mathrm{C} 3 \\
\mathrm{~B} 4-\mathrm{C} 4, \mathrm{~B} 5-\mathrm{C} 5\end{array}$ & 1269.98 & 18.53 \\
\hline \multicolumn{4}{|c|}{ Beams along } \\
\hline \multicolumn{4}{|l|}{$\mathrm{x}$-axis } \\
\hline \multirow{2}{*}{ Roof } & A1-A6, C1-C6 & 379.40 & 5.54 \\
\hline & B1-B6 & 758.80 & 11.07 \\
\hline \multirow{2}{*}{ Floor } & A1-A6, C1-C6 & 550.00 & 8.03 \\
\hline & B1-B6 & 1101.30 & 16.07 \\
\hline
\end{tabular}

weights have been found with other metaheuristic algorithms; namely $128637.77 \mathrm{lb}(58349.11 \mathrm{~kg})$ by ES, $128788.82 \mathrm{lb}$ $(58417.63 \mathrm{~kg})$ by $\mathrm{SA}, 131782.50 \mathrm{lb}(59775.54 \mathrm{~kg})$ by TS, $133330.09 \mathrm{lb}(60477.51 \mathrm{~kg})$ by ACO, $135185.87 \mathrm{lb}$ (61319.28 kg) by PSO, $138830.09 \mathrm{lb}(62972.27 \mathrm{~kg})$ by HS, and $141846.24 \mathrm{lb}(64340.37 \mathrm{~kg})$ by SGA. The convergence curve for the best feasible design obtained in the course of optimization using the ADS algorithm is plotted in Fig. 5.

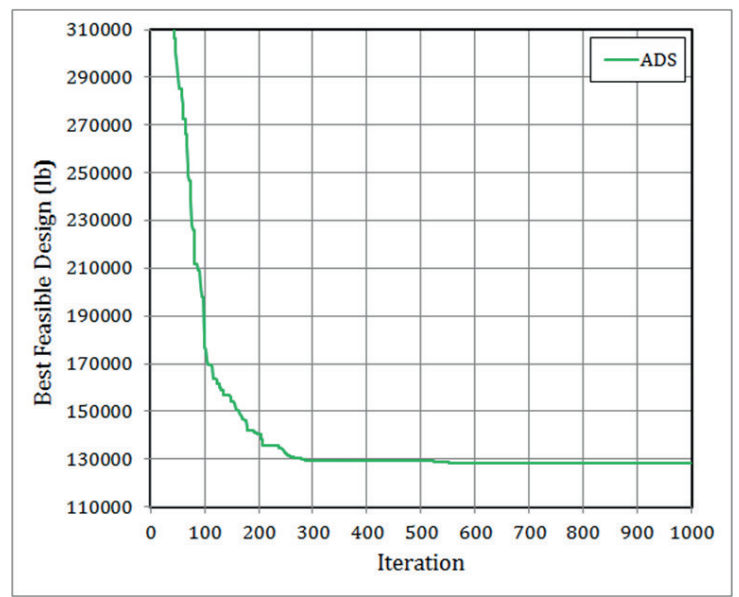

Fig. 5 Optimization history for 325-member braced steel frame using ADS

Table 4 Comparison of results for 325-member braced steel frame

\begin{tabular}{|c|c|c|c|c|c|c|c|c|}
\hline Member Group & ES & SA & $\mathrm{TS}$ & $\mathrm{ACO}$ & PSO & HS & SGA & ADS \\
\hline 1 & W8X40 & W18X40 & W12X35 & W16X57 & W18X55 & W18X60 & $\mathrm{W} 12 \mathrm{X} 30$ & W16X45 \\
\hline 2 & W8X24 & W8X24 & W8X24 & W6X25 & W16X40 & $\mathrm{W} 12 \mathrm{X} 50$ & W18X40 & W16X40 \\
\hline 3 & W21X62 & W18X60 & W12X53 & W21X68 & W14X61 & W14X61 & W24X68 & W10X26 \\
\hline 4 & W6X15 & W6X15 & W6X20 & W6X15 & W6X15 & W8X18 & W5X19 & W18X60 \\
\hline 5 & W18X50 & W16X45 & W18X50 & W8X40 & $\mathrm{W} 12 \mathrm{X} 40$ & W16X45 & W14X43 & W12X14 \\
\hline 6 & W12X14 & W12X14 & W10X17 & W12X14 & W12X16 & W10X15 & W10X19 & W18X40 \\
\hline 7 & W18X40 & W18X40 & W18X40 & W21X44 & W21X44 & W18X40 & W18X46 & W6X15 \\
\hline 8 & W8X18 & W8X24 & W8X21 & W8X24 & W8X18 & W16X31 & W10X26 & W21X44 \\
\hline 9 & W8X18 & $\mathrm{W} 14 \mathrm{X} 22$ & W6X15 & W8X21 & W10X22 & W14X30 & W14X22 & W8X21 \\
\hline 10 & W12X50 & W12X50 & W14X53 & W14X48 & W16X50 & W12X53 & W12X50 & W10X19 \\
\hline 11 & W6X15 & W6X15 & W6X15 & W6X15 & W6X15 & W6X15 & W6X20 & W12X50 \\
\hline 12 & W21X44 & W21X44 & W18X46 & W16X50 & W8X48 & $\mathrm{W} 12 \times 50$ & W18X46 & W12X14 \\
\hline 13 & W12X14 & W12X14 & W12X16 & W12X14 & W12X44 & W12X16 & W12X19 & W18X40 \\
\hline 14 & W18X40 & W18X40 & W18X40 & W18X40 & W21X44 & W18X40 & W18X40 & W6X15 \\
\hline 15 & W8X13 & W8X13 & W8X15 & W8X15 & W8X18 & W8X15 & W12X19 & W14X34 \\
\hline 16 & W12X14 & W12X14 & W12X14 & W12X19 & W12X14 & W12X16 & W8X24 & W8X13 \\
\hline 17 & W14X34 & W14X34 & W16X36 & W14X34 & W16X36 & W10X33 & W12X35 & W8X13 \\
\hline 18 & W6X15 & W6X15 & W5X16 & W6X15 & W6X15 & W6X15 & W6X20 & W14X34 \\
\hline 19 & W14X34 & W14X34 & W14X34 & W14X34 & W16X36 & W12X45 & W14X30 & W12X14 \\
\hline 20 & W12X14 & W12X14 & W12X14 & W12X16 & W12X14 & W12X14 & W12X16 & W18X40 \\
\hline 21 & W18X40 & W18X40 & W18X40 & W18X40 & W18X40 & W18X40 & W21X44 & W6X15 \\
\hline Weight, lb (kg) & $\begin{array}{l}128637.77 \\
(58349.11)\end{array}$ & $\begin{array}{l}128788.82 \\
(58417.63)\end{array}$ & $\begin{array}{c}131782.50 \\
(59775.54)\end{array}$ & $\begin{array}{l}133330.09 \\
(60477.51)\end{array}$ & $\begin{array}{l}135185.87 \\
(61319.28)\end{array}$ & $\begin{array}{l}138830.09 \\
(62972.27)\end{array}$ & $\begin{array}{c}141846.24 \\
(64340.37)\end{array}$ & $\begin{array}{c}128320.45 \\
(58205.177)\end{array}$ \\
\hline
\end{tabular}




\subsection{Example 3: 568-member unbraced steel frame}

The third design instance is an unbraced space steel frame (Fig. 6) composed of 256 joints and 568 members which are collected in 25 member groups. This optimization example has been already studied in Hasançebi et al. [31] using various metaheuristics. The frame is subjected to two loading conditions of combined gravity and wind forces. The wind forces are calculated based on a basic wind speed of $105 \mathrm{mph}(46.94 \mathrm{~m} / \mathrm{s})$. The resulting gravity loading on the beams of roof and floors is tabulated in Table 5 and the wind loading is given in Table 6 . In the first loading condition, gravity loading is applied with wind loading acting along $\mathrm{x}$-axis, whereas in the second one wind loading is acted along $\mathrm{y}$-axis.

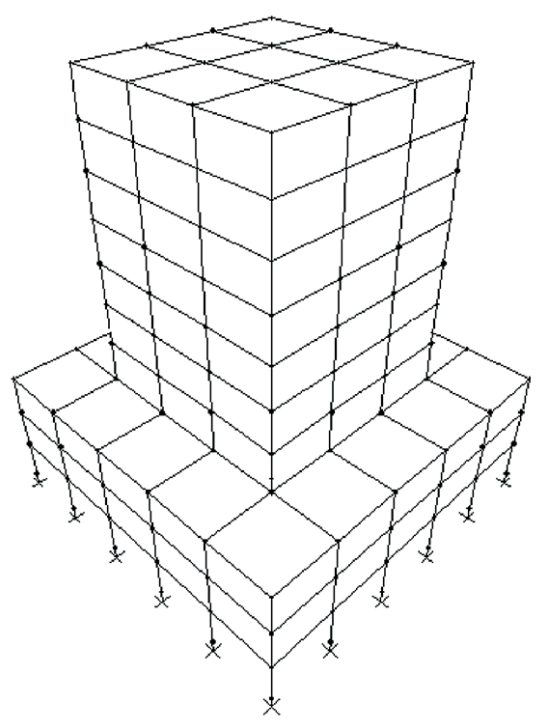

(a)

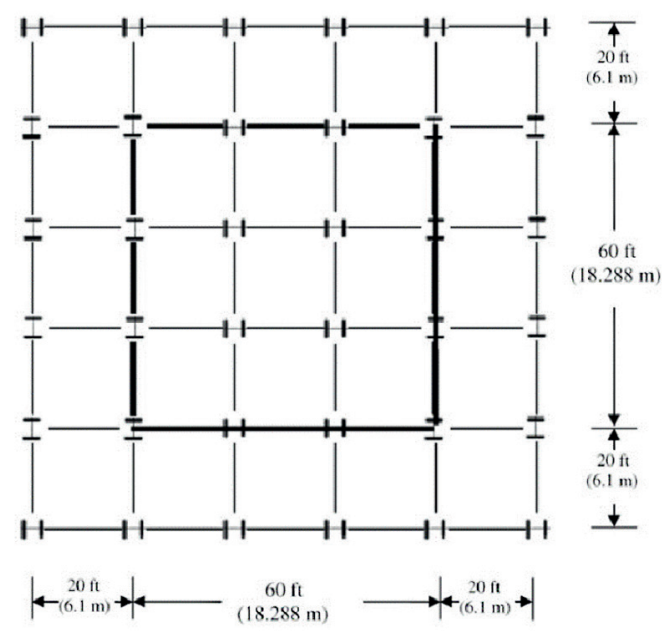

(c)
Table 5 Gravity loading on the beams of 568-member unbraced steel frame

\begin{tabular}{lcccc}
\hline Beam Type & \multicolumn{4}{c}{ Uniformly Distributed Load } \\
& \multicolumn{2}{c}{ Outer Beams } & \multicolumn{2}{c}{ Inner Beams } \\
& $(\mathrm{lb} / \mathrm{ft})$ & $(\mathrm{kN} / \mathrm{m})$ & $(\mathrm{lb} / \mathrm{ft})$ & $(\mathrm{kN} / \mathrm{m})$ \\
\hline Roof beams & 505.88 & 7.38 & 1011.74 & 14.77 \\
Floor beams & 734.20 & 10.72 & 1468.40 & 21.44 \\
\hline
\end{tabular}

Optimization of the 568-member unbraced steel frame is carried out using the ADS algorithm and the results achieved as well as sectional designations for member groups are presented and compared to the results of other metaheuristics reported in Hasançebi et al. [31]. As can be seen from Table 7 the ADS algorithm finds a promising solution

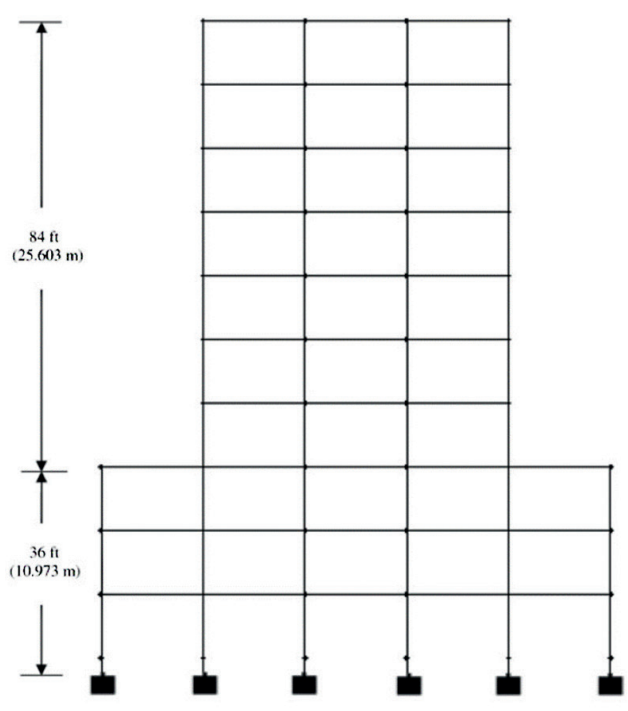

(b)

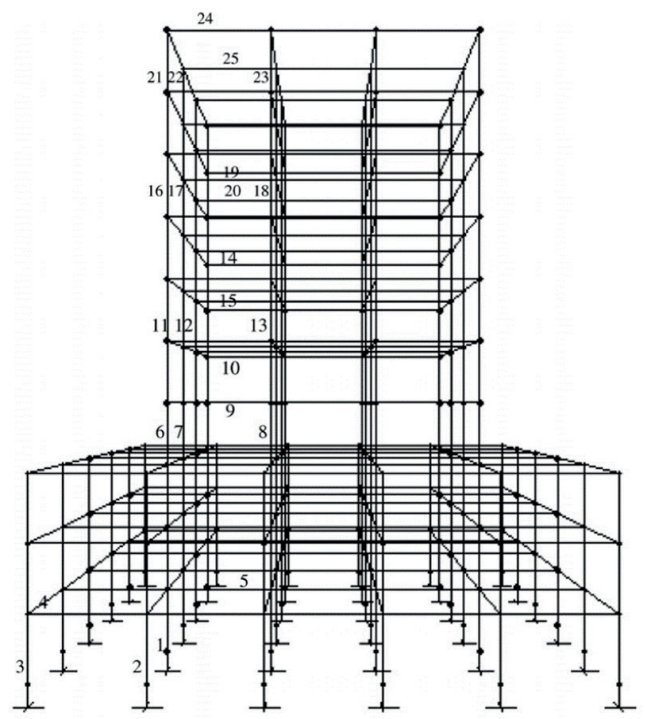

(d)

Fig. 6 568-member unbraced steel frame: (a) 3D view, (b) elevation view, (c) plan view, (d) member grouping 
Table 6 Wind loading on 568-member unbraced steel frame

\begin{tabular}{lcccc}
\hline Floor No & \multicolumn{2}{c}{ Windward } & \multicolumn{2}{c}{ Leeward } \\
& $(\mathrm{lb} / \mathrm{ft})$ & $(\mathrm{kN} / \mathrm{m})$ & $(\mathrm{lb} / \mathrm{ft})$ & $(\mathrm{kN} / \mathrm{m})$ \\
\hline 1 & 112.51 & 1.64 & 127.38 & 1.86 \\
2 & 128.68 & 1.88 & 127.38 & 1.86 \\
3 & 144.68 & 2.10 & 127.38 & 1.86 \\
4 & 156.86 & 2.29 & 127.38 & 1.86 \\
5 & 167.19 & 2.44 & 127.38 & 1.86 \\
6 & 176.13 & 2.57 & 127.38 & 1.86 \\
7 & 184.06 & 2.69 & 127.38 & 1.86 \\
8 & 191.21 & 2.79 & 127.38 & 1.86 \\
9 & 197.76 & 2.89 & 127.38 & 1.86 \\
10 & 101.90 & 1.49 & 63.90 & 1.86 \\
\hline
\end{tabular}

with a design weight of $505781.22 \mathrm{lb}(229418.50 \mathrm{~kg})$ which is slightly heavier than the best solution found by ES, i.e. $503953.63 \mathrm{lb}(228588.33 \mathrm{~kg})$. Here, relatively higher design weights have been obtained using other metaheuristic algorithms; namely $526370.76 \mathrm{lb}(238756.51 \mathrm{~kg})$ by SA, $518458.35 \mathrm{lb}(235167.52 \mathrm{~kg})$ by TS, $532353.70 \mathrm{lb}$
$(241470.31 \mathrm{~kg})$ by ACO, $558346.15 \mathrm{lb}(253260.23 \mathrm{~kg})$ by PSO, $571159.66 \mathrm{lb}(259072.31 \mathrm{~kg})$ by HS, and $541380.54 \mathrm{lb}$ $(245564.80 \mathrm{~kg})$ by SGA. The convergence curve for the best feasible design obtained in the course of optimization using the ADS algorithm is depicted in Fig. 7.

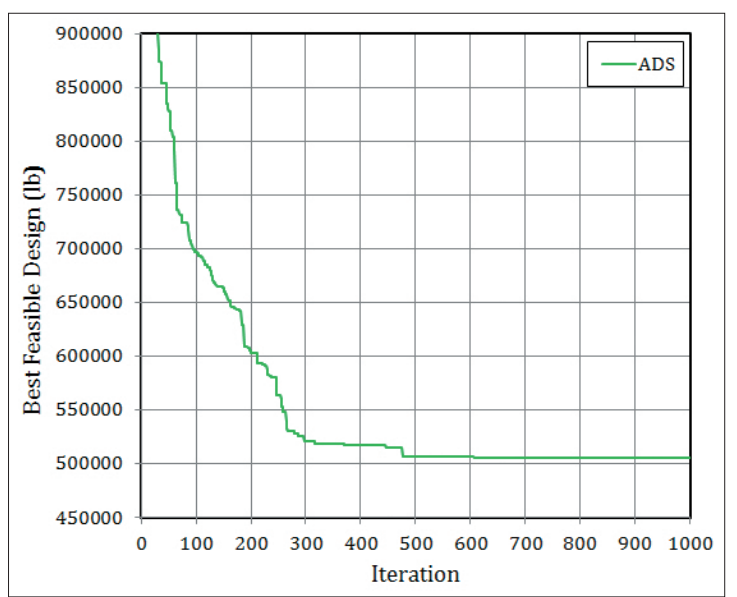

Fig. 7 Optimization history for 568-member unbraced steel frame using ADS

Table 7 Comparison of results for 568-member unbraced steel frame

\begin{tabular}{|c|c|c|c|c|c|c|c|c|}
\hline Member Group & $\mathrm{ES}$ & $\mathrm{TS}$ & SA & $\mathrm{ACO}$ & SGA & PSO & HS & ADS \\
\hline 1 & W14X193 & W14X193 & W14X193 & W14X193 & W14X193 & W14X159 & W14X176 & W14X193 \\
\hline 2 & W8X48 & W8X48 & W8X48 & W8X48 & W8X48 & W24X76 & W12X53 & W10X45 \\
\hline 3 & W10X39 & W8X40 & W8X40 & W10X45 & W10X39 & W10X39 & W8X40 & W8X48 \\
\hline 4 & W10X22 & W10X22 & W10X22 & W10X22 & W10X26 & W10X22 & W10X22 & W10X22 \\
\hline 5 & W21X50 & W21X50 & W21X44 & W21X50 & W21X50 & W24X55 & W24X55 & W21X50 \\
\hline 6 & W10X54 & W10X54 & W12X65 & W14X61 & W18X76 & W12X72 & W24X117 & W12X58 \\
\hline 7 & W14X109 & W14X120 & W14X145 & W14X120 & W14X109 & W27X146 & W24X146 & W14X109 \\
\hline 8 & W14X176 & W14X159 & W14X145 & W40X192 & W40X192 & W27X217 & W40X199 & W14X159 \\
\hline 9 & W18X40 & W21X44 & W24X68 & W18X35 & W18X40 & W18X40 & W21X44 & W18X35 \\
\hline 10 & W18X40 & W18X40 & W24X55 & W18X40 & W21X50 & W18X40 & W18X40 & W21X50 \\
\hline 11 & W10X49 & W10X45 & W10X49 & W12X58 & W12X65 & W18X71 & W27X94 & W10X49 \\
\hline 12 & W14X90 & W14X90 & W14X90 & W12X96 & W21X111 & W21X101 & W14X120 & W14X90 \\
\hline 13 & W14X109 & W12X120 & W14X120 & W12X136 & W12X152 & W14X176 & W14X120 & W14X120 \\
\hline 14 & W14X30 & W21X44 & W16X36 & W12X30 & W12X30 & W14X34 & W12X30 & W14X30 \\
\hline 15 & W16X36 & W16X36 & W16X40 & W21X44 & W16X40 & W21X44 & W18X40 & W16X36 \\
\hline 16 & W12X45 & W10X33 & $\mathrm{W} 12 \mathrm{X} 40$ & W8X58 & W14X68 & W12X65 & W27X94 & W8X48 \\
\hline 17 & W12X65 & W12X65 & W12X65 & W18X76 & W18X76 & W10X68 & W18X97 & W12X65 \\
\hline 18 & W10X22 & W14X34 & W12X26 & W12X35 & W8X28 & W12X35 & W12X30 & W10X22 \\
\hline 19 & W12X79 & W12X79 & W12X72 & W10X88 & W10X88 & W12X79 & W10X88 & W12X79 \\
\hline 20 & W14X30 & W14X30 & W16X36 & W14X30 & W16X36 & W14X38 & W18X35 & W14X30 \\
\hline 21 & W8X35 & W10X39 & W8X24 & W8X58 & W8X48 & W10X39 & W12X72 & W8X35 \\
\hline 22 & W10X39 & W12X45 & W10X49 & W8X40 & W14X34 & W8X31 & W10X45 & W16X40 \\
\hline 23 & W8X31 & W12X35 & W8X24 & W8X31 & W12X30 & W12X96 & W14X132 & W10X49 \\
\hline 24 & W8X18 & W6X20 & W12X26 & W8X24 & W8X21 & W12X26 & W18X35 & W8X18 \\
\hline 25 & W14X30 & W12X26 & W12X26 & W16X45 & W18X35 & W12X26 & W16X36 & W12X26 \\
\hline Weight, lb (kg) & $\begin{array}{c}503953.63 \\
(228588.33)\end{array}$ & $\begin{array}{c}518458.35 \\
(235167.52)\end{array}$ & $\begin{array}{c}526370.76 \\
(238756.51)\end{array}$ & $\begin{array}{c}532353.70 \\
(241470.31)\end{array}$ & $\begin{array}{c}541380.54 \\
(245564.80)\end{array}$ & $\begin{array}{c}558346.15 \\
(253260.23)\end{array}$ & $\begin{array}{c}571159.66 \\
(259072.31)\end{array}$ & $\begin{array}{c}505781.22 \\
(229418.50)\end{array}$ \\
\hline
\end{tabular}




\subsection{Example 4: 744-member unbraced steel frame}

The fourth design optimization instance is an unbraced space steel frame composed of 315 joints and 744 structural members which are collected in 16 different member groups. Fig. 8 depicts the side, plan, and 3D views of the frame as well as the corresponding member grouping details. This test example has been formerly investigated in Hasançebi et al. [32]. The frame is subjected to two loading conditions of combined gravity and wind forces as follows. The uniformly distributed gravity loads of $379.4 \mathrm{lb} / \mathrm{ft}$ $(5.54 \mathrm{kN} / \mathrm{m})$ and $758.8 \mathrm{lb} / \mathrm{ft}(11.08 \mathrm{kN} / \mathrm{m})$ are applied on the exterior and interior top story beams, respectively, whereas exterior and interior beams of the other floors are subjected to uniformly distributed gravity loads of $550.65 \mathrm{lb} / \mathrm{ft}$ $(8.04 \mathrm{kN} / \mathrm{m})$ and $1101.3 \mathrm{lb} / \mathrm{ft}(16.08 \mathrm{kN} / \mathrm{m})$, respectively.
Here, the design wind speed is taken as $121 \mathrm{mph}(54.09 \mathrm{~m} / \mathrm{s})$ and the corresponding lateral (wind) loads acting at each floor level on windward and leeward faces of the frame are presented in Table 8 . In the first loading case, the gravity loads are applied together with the wind loads acting along the $\mathrm{x}$-axis, whereas in the second case they are applied together with the wind loads acting along the y-axis. The combined stress, stability, displacement and geometric constraints are imposed according to the provisions of AISC-ASD [22], as given in Section 2.

Discrete sizing optimization of the 744-member steel frame is performed using the ADS algorithm and the obtained results are compared to the previously reported designs in Hasançebi et al. [32] using different metaheuristic techniques, namely standard harmony search (HS),

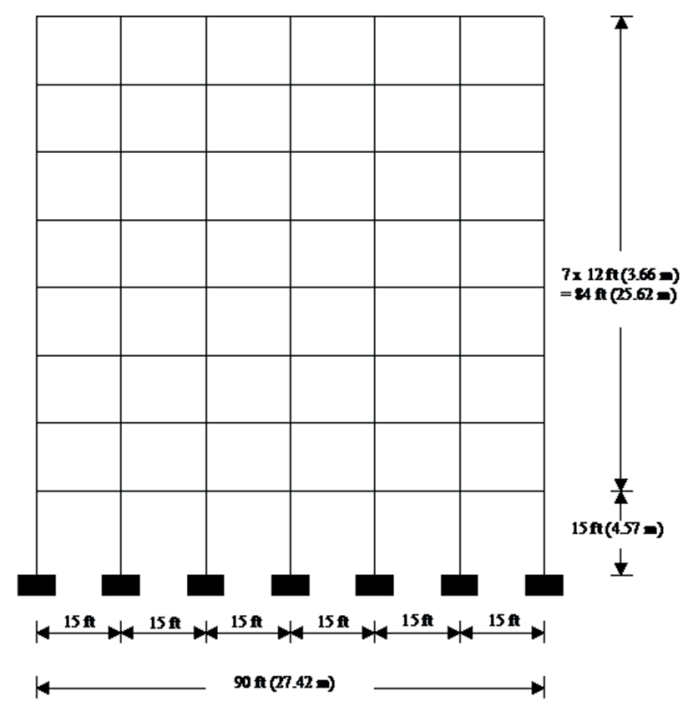

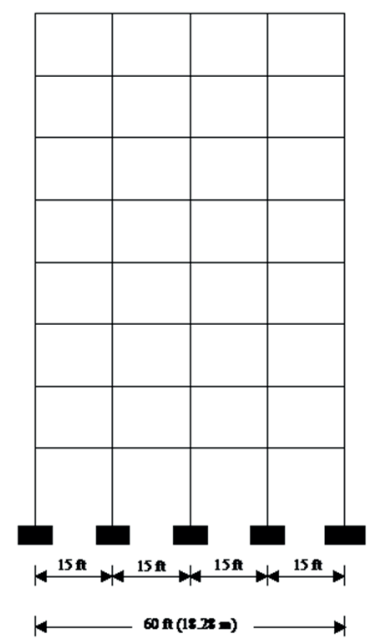

(b)

(a)
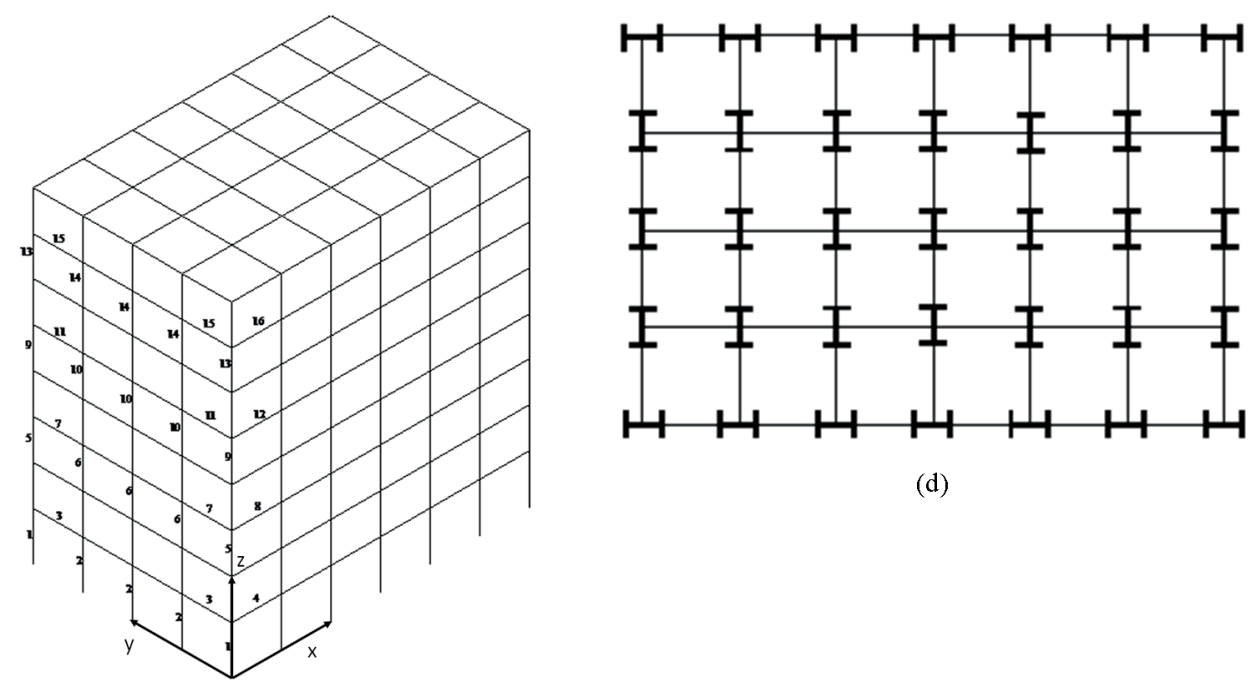

(d)

Fig. 8 744-member unbraced steel frame: (a) side view (x-z plane), (b) side view (y-z plane), (c) 3D view, (d) plan view 
Table 8 Wind forces on 744-member unbraced steel frame

\begin{tabular}{lcccc}
\hline Floor No & \multicolumn{2}{c}{ Windward } & \multicolumn{2}{c}{ Leeward } \\
& $(\mathrm{lb} / \mathrm{ft})$ & $(\mathrm{kN} / \mathrm{m})$ & $(\mathrm{lb} / \mathrm{ft})$ & $(\mathrm{kN} / \mathrm{m})$ \\
\hline 1 & 140.64 & 0.63 & 159.22 & 0.71 \\
2 & 171.44 & 0.76 & 159.22 & 0.71 \\
3 & 192.49 & 0.86 & 159.22 & 0.71 \\
4 & 208.98 & 0.93 & 159.22 & 0.71 \\
5 & 222.74 & 0.99 & 159.22 & 0.71 \\
6 & 234.65 & 1.04 & 159.22 & 0.71 \\
7 & 245.22 & 1.09 & 159.22 & 0.71 \\
8 & 127.38 & 0.57 & 79.61 & 0.36 \\
\hline
\end{tabular}

adaptive harmony search (AHS), tabu search (TS), ant colony optimization (ACO), particle swarm optimization (PSO), and simple genetic algorithm (SGA). As tabulated in Table 9, the ADS algorithm produces a design weight of $399650.79 \mathrm{lb}(181281.56 \mathrm{~kg})$ which is slightly heavier than the best solution found by AHS, i.e. $395708.03 \mathrm{lb}$ $(179493.16 \mathrm{~kg})$. For this test example, relatively higher design weights have been achieved using other metaheuristic techniques; namely $420177.57 \mathrm{lb}(190592.55 \mathrm{~kg})$ by HS, $401647.84 \mathrm{lb}(182136.90 \mathrm{~kg})$ by TS, $405441.65 \mathrm{lb}$ $(183908.33 \mathrm{~kg})$ by ACO, $412200.98 \mathrm{lb}(186974.36 \mathrm{~kg})$ by PSO, and $424076.52 \mathrm{lb}(192361.11 \mathrm{~kg})$ by SGA.

\subsection{Example 5: 1860-member braced steel frame}

The last design example investigated in the present study is a 36-story braced steel frame composed of 814 joints and 1860 structural members. This design optimization instance has been formerly studied in Hasançebi and Kazemzadeh Azad [33] as well as Saka and Hasançebi [34] using metaheuristic techniques. The side, top and 3D views of the frame as well as member grouping details are shown in Fig. 9. An economical and effective stiffening of the frame against lateral forces is achieved through exterior diagonal bracing members located on the perimeter of the building, which also participate in transmitting the gravity forces.

The wide-flange (W) profile list consisting of 297 ready sections is used to size the column members, while beams and diagonals are taken from discrete sets of 171 and 147 economical sections selected from wide-flange profile list based on cross sectional area and moment of inertia properties in the former, and on area and radius of gyration properties in the latter. The 1860 frame members are collected in 72 different member groups, considering the symmetry of the structure and practical fabrication requirements. That is, the columns in a story are collected in three member groups as corner columns, inner columns and outer columns, whereas beams are divided into two

Table 9 Comparison of results for 744-member unbraced steel frame

\begin{tabular}{|c|c|c|c|c|c|c|c|}
\hline Member Group & AHS & HS & $\mathrm{TS}$ & $\mathrm{ACO}$ & PSO & SGA & ADS \\
\hline 1 & W12X87 & W12X79 & W8X35 & W12X72 & W14X99 & W24X68 & W12X79 \\
\hline 2 & W14X109 & W14X132 & W14X145 & W14X109 & W14X99 & W14X120 & W14X109 \\
\hline 3 & W10X22 & W14X22 & W16X26 & W14X22 & W8X18 & W8X21 & W14X22 \\
\hline 4 & W18X35 & W16X36 & W18X35 & W18X40 & W21X44 & W21X44 & W18X40 \\
\hline 5 & W12X65 & W12X72 & W8X24 & W10X49 & W14X48 & W12X65 & W10X54 \\
\hline 6 & W12X79 & W12X87 & W14X90 & W12X87 & W14X90 & W12X79 & W12X79 \\
\hline 7 & W10X22 & W14X22 & W14X22 & W12X26 & W16X31 & W14X26 & W14X22 \\
\hline 8 & W16X26 & W16X26 & W18X35 & W16X26 & W14X26 & W16X26 & W16X31 \\
\hline 9 & W8X31 & W16X40 & W10X54 & W12X35 & W8X31 & W8X35 & W14X43 \\
\hline 10 & W12X65 & W12X65 & W12X53 & $\mathrm{W} 12 \times 72$ & W14X90 & $\mathrm{W} 12 \times 72$ & $\mathrm{~W} 12 \mathrm{X} 72$ \\
\hline 11 & $\mathrm{~W} 14 \mathrm{X} 22$ & $\mathrm{~W} 14 \mathrm{X} 22$ & W6X20 & $\mathrm{W} 14 \mathrm{X} 22$ & W8X18 & $\mathrm{W} 14 \mathrm{X} 26$ & W8X18 \\
\hline 12 & W14X22 & W16X26 & $\mathrm{W} 16 \times 26$ & $\mathrm{~W} 16 \times 26$ & $\mathrm{~W} 16 \times 26$ & $\mathrm{~W} 14 \mathrm{X} 22$ & $\mathrm{~W} 14 \mathrm{X} 22$ \\
\hline 13 & W6X20 & W16X36 & W8X24 & W10X39 & W8X31 & W8X35 & $\mathrm{W} 12 \mathrm{X} 26$ \\
\hline 14 & W12X58 & W8X35 & W8X40 & W8X35 & W8X31 & W8X35 & W10X45 \\
\hline 15 & W8X18 & W10X22 & W8X18 & W8X21 & W8X18 & W8X21 & W8X18 \\
\hline 16 & $\mathrm{~W} 14 \mathrm{X} 22$ & $\mathrm{~W} 14 \mathrm{X} 22$ & $\mathrm{~W} 14 \mathrm{X} 26$ & $\mathrm{~W} 10 \mathrm{X} 22$ & $\mathrm{~W} 14 \mathrm{X} 22$ & W18X35 & W14X22 \\
\hline $\begin{array}{l}\text { Weight, lb } \\
(\mathrm{kg})\end{array}$ & $\begin{array}{c}395708.03 \\
(179493.16)\end{array}$ & $\begin{array}{c}420177.57 \\
(190592.55)\end{array}$ & $\begin{array}{c}401647.84 \\
(182136.90)\end{array}$ & $\begin{array}{c}405441.65 \\
(183908.33)\end{array}$ & $\begin{array}{c}412200.98 \\
(186974.36)\end{array}$ & $\begin{array}{c}424076.52 \\
(192361.11)\end{array}$ & $\begin{array}{c}399650.79 \\
(181281.56)\end{array}$ \\
\hline
\end{tabular}




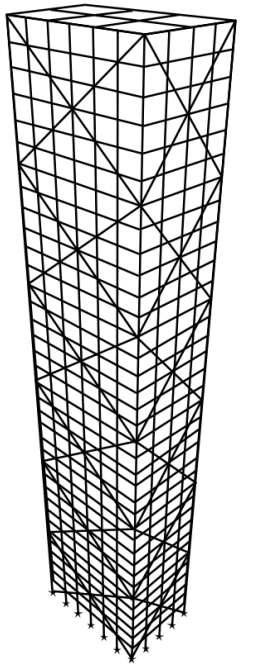

(a)

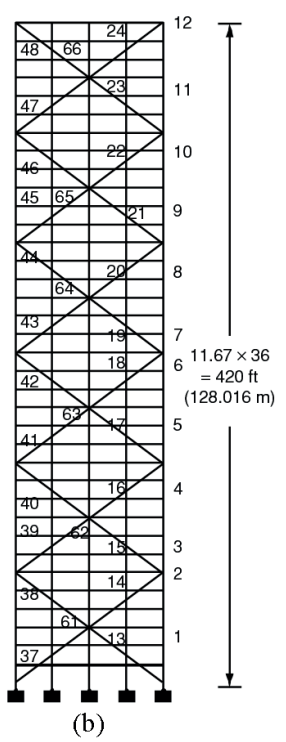

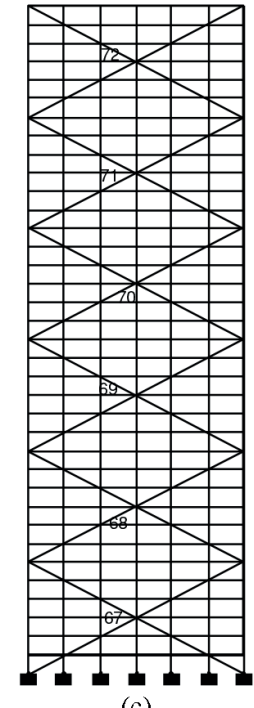

(c)

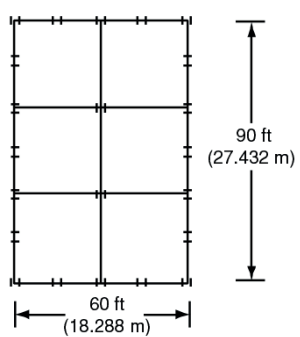

(d)

Fig. 9 Schematic of the spatial 1860-member braced, (a) 3-D view, (b) front view and member grouping, (c) side view, (d) top view

groups as inner beams and outer beams. The corner columns are grouped together as having the same section over three adjacent stories, as are inner columns, outer columns, inner beams and outer beams. Bracing members on each facade are designed as three-story deep members, and two bracing groups are specified at every six stories.

The 1860-member braced space steel frame is subjected to two loading conditions of combined gravity and wind forces. These forces are computed as per ASCE 7-05 [30] based on the following design values: a design dead load of $2.88 \mathrm{kN} / \mathrm{m}^{2}\left(60.13 \mathrm{lb} / \mathrm{ft}^{2}\right)$, a design live load of $2.39 \mathrm{kN} / \mathrm{m}^{2}$ $\left(50 \mathrm{lb} / \mathrm{ft}^{2}\right)$, a ground snow load of $1.20 \mathrm{kN} / \mathrm{m}^{2}\left(25 \mathrm{lb} / \mathrm{ft}^{2}\right)$ and a basic wind speed of $55.21 \mathrm{~m} / \mathrm{s}(123.5 \mathrm{mph})$. Lateral (wind) loads acting at each floor level on windward and leeward faces of the frame are tabulated in Table 10 and the gravity loading on the beams of roof and floors is given in Table 11. In the first loading condition, gravity loads are applied together with wind loads acting along $\mathrm{x}$-axis $(1.0 \mathrm{GL}+1.0 \mathrm{WL}-\mathrm{x})$, whereas in the second loading condition they are applied with wind loads acting along y-axis $(1.0 \mathrm{GL}+1.0 \mathrm{vWL}-\mathrm{y})$. The joint displacements in $\mathrm{x}$ and $\mathrm{y}$-directions are restricted to $32.0 \mathrm{~cm}$ (12.6 in) which corresponds to $1 / 400$ of the frame height. Moreover, story drift constraints are imposed at each story of the frame which is equal to $1 / 400$ of story height.

Optimal sizing of the 1860-member braced steel frame is carried out using the ADS algorithm and the results are compared to the previously reported designs in the literature using the bat-Inspired (BI) [33] and AHS [34] algorithms. As given in Table 12, the ADS algorithm obtains a promising design weight of 4858.33 kips (2203.7 tons) which is slightly heavier than the best solution found by BI algorithm, i.e. 4822.6 kips (2187.5 tons). For this design optimization example, a relatively higher design weight of 5254.9 kips (2383.6 tons) has been achieved using AHS algorithm.

It is worth mentioning that, although in this study the application of the ADS algorithm is limited to single-objective optimization problems, it is possible to reformulate the algorithm to handle multi-objective optimization instances as well. Moreover, akin to other metaheuristics, the ADS algorithm does not guarantee the convergence to a global optimum. However, as shown in the present study, comparison of the performance of the ADS versus other contemporary metaheuristics clearly indicates the efficiency of this technique in optimum design of real size steel frames. Finally, it should be noted that the conclusions drawn in this study are valid for the investigated test examples only and may not be valid for the cases not investigated here.

\section{Conclusions}

In this study, a recently developed metaheuristic optimization algorithm, namely adaptive dimensional search technique, is applied to discrete sizing optimization of realsize steel frames. Beside the simple algorithmic structure and efficiency of the algorithm, an important feature of the ADS is that its working principles are not based on any metaphor. Instead, the algorithm uses an efficient performance-oriented methodology for searching the optimum in the design space. The performance of the ADS is investigated using five practical instances of steel frames and the obtained results are compared to those of several metaheuristic techniques available in the literature. 
The comparison of the numerical results indicates that the ADS algorithm can be efficiently employed for sizing optimization of steel frames under realistic design constraints. There is scope for further research to reformulate the ADS algorithm for handling multi-objective optimization problems as well as other engineering design instances such as optimum design of reinforced concrete frames or other composite structural systems.

Table 10 Wind loads acting on the spatial 1860-member braced steel frame

\begin{tabular}{|c|c|c|}
\hline Floor & Windward kN/m (lb/ft) & LeewardkN/m (lb/ft) \\
\hline 1 & $2.05(140.64)$ & $3.57(244.70)$ \\
\hline 2 & $2.50(171.44)$ & $3.57(244.70)$ \\
\hline 3 & $2.81(192.49)$ & $3.57(244.70)$ \\
\hline 4 & $3.05(208.98)$ & $3.57(244.70)$ \\
\hline 5 & $3.25(222.74)$ & $3.57(244.70)$ \\
\hline 6 & $3.42(234.65)$ & $3.57(244.70)$ \\
\hline 7 & $3.58(245.22)$ & $3.57(244.70)$ \\
\hline 8 & $3.72(254.75)$ & $3.57(244.70)$ \\
\hline 9 & $3.85(263.47)$ & $3.57(244.70)$ \\
\hline 10 & $3.96(271.52)$ & $3.57(244.70)$ \\
\hline 11 & $4.07(279.02)$ & $3.57(244.70)$ \\
\hline 12 & $4.18(286.04)$ & $3.57(244.70)$ \\
\hline 13 & $4.27(292.66)$ & $3.57(244.70)$ \\
\hline 14 & $4.36(298.92)$ & $3.57(244.70)$ \\
\hline 15 & $4.45(304.87)$ & $3.57(244.70)$ \\
\hline 16 & $4.53(310.55)$ & $3.57(244.70)$ \\
\hline 17 & $4.61(315.97)$ & $3.57(244.70)$ \\
\hline 18 & 4.69 (321.18) & $3.57(244.70)$ \\
\hline 19 & $4.76(326.18)$ & $3.57(244.70)$ \\
\hline 20 & 4.83 (330.99) & $3.57(244.70)$ \\
\hline 21 & $4.90(335.64)$ & $3.57(244.70)$ \\
\hline 22 & 4.97 (340.13) & $3.57(244.70)$ \\
\hline 23 & $5.03(344.48)$ & $3.57(244.70)$ \\
\hline 24 & 5.09 (348.69) & $3.57(244.70)$ \\
\hline 25 & $5.15(352.78)$ & $3.57(244.70)$ \\
\hline 26 & $5.21(356.76)$ & $3.57(244.70)$ \\
\hline 27 & $5.27(360.62)$ & $3.57(244.70)$ \\
\hline 28 & $5.32(364.39)$ & $3.57(244.70)$ \\
\hline 29 & $5.37(368.06)$ & $3.57(244.70)$ \\
\hline 30 & $5.43(371.65)$ & $3.57(244.70)$ \\
\hline 31 & $5.48(375.14)$ & $3.57(244.70)$ \\
\hline 32 & $5.53(378.56)$ & $3.57(244.70)$ \\
\hline 33 & $5.58(381.90)$ & $3.57(244.70)$ \\
\hline 34 & $5.62(385.18)$ & $3.57(244.70)$ \\
\hline 35 & $5.67(388.38)$ & $3.57(244.70)$ \\
\hline 36 & $2.86(195.76)$ & $1.79(122.35)$ \\
\hline
\end{tabular}

Table 11 Gravity loads acting on the spatial 1860-member braced steel frame

\begin{tabular}{cccc}
\hline \multirow{2}{*}{ Beam Type } & \multicolumn{2}{c}{ Uniformly Distributed Load, kN/m (lb/ft) } \\
& Dead Load & Live Load & Snow Load \\
\hline Roof beams & $22.44(1536.66)$ & N.A & $5.88(402.50)$ \\
Floor beams & $22.44(1536.66)$ & $18.66(1277.78)$ & N.A \\
\hline
\end{tabular}


Table 12 Comparison of results for 1860-member braced steel frame

\begin{tabular}{|c|c|c|c|c|c|c|c|c|c|c|c|}
\hline \multirow{2}{*}{$\begin{array}{l}\text { Member } \\
\text { Group }\end{array}$} & \multicolumn{3}{|c|}{ AHS } & \multirow{2}{*}{$\begin{array}{l}\text { Member } \\
\text { Group }\end{array}$} & \multicolumn{3}{|c|}{ BI } & \multirow{2}{*}{$\begin{array}{c}\text { Member } \\
\text { Group }\end{array}$} & \multicolumn{3}{|c|}{ ADS } \\
\hline & Section & $\begin{array}{l}\text { Member } \\
\text { Group }\end{array}$ & Section & & Section & $\begin{array}{l}\text { Member } \\
\text { Group }\end{array}$ & Section & & Section & $\begin{array}{l}\text { Member } \\
\text { Group }\end{array}$ & Section \\
\hline 1 & W24X370 & 37 & W12X14 & 1 & W14X398 & 37 & W12X16 & 1 & W14X398 & 37 & W12X16 \\
\hline 2 & W12X336 & 38 & W16X26 & 2 & W40X531 & 38 & W12X19 & 2 & W40X531 & 38 & W12X19 \\
\hline 3 & W12X305 & 39 & W14X22 & 3 & W24X306 & 39 & W10X22 & 3 & W24X306 & 39 & W12X26 \\
\hline 4 & W12X190 & 40 & W14X26 & 4 & W18X258 & 40 & W8X24 & 4 & W40X244 & 40 & W8X24 \\
\hline 5 & W14X193 & 41 & W27X102 & 5 & W14X109 & 41 & W12X26 & 5 & W14X109 & 41 & W12X30 \\
\hline 6 & W24X117 & 42 & W16X31 & 6 & W27X114 & 42 & W14X38 & 6 & W14X145 & 42 & W12X35 \\
\hline 7 & W12X79 & 43 & W18X35 & 7 & W33X152 & 43 & W12X26 & 7 & W33X152 & 43 & W12X26 \\
\hline 8 & W12X79 & 44 & W18X35 & 8 & W24X192 & 44 & W44X198 & 8 & W24X192 & 44 & W44X198 \\
\hline 9 & W40X244 & 45 & W40X167 & 9 & W30X116 & 45 & W14X26 & 9 & W30X116 & 45 & W14X26 \\
\hline 10 & W18X86 & 46 & W14X22 & 10 & W24X146 & 46 & W14X26 & 10 & W24X146 & 46 & W14X26 \\
\hline 11 & W12X96 & 47 & W24X68 & 11 & W16X40 & 47 & W14X30 & 11 & W16X40 & 47 & W16X36 \\
\hline 12 & W8X28 & 48 & W16X26 & 12 & W12X136 & 48 & W24X68 & 12 & W21X122 & 48 & W24X68 \\
\hline 13 & W33X424 & 49 & W24X62 & 13 & W27X448 & 49 & W21X62 & 13 & W27X448 & 49 & W21X62 \\
\hline 14 & W40X436 & 50 & W27X94 & 14 & W24X370 & 50 & W24X68 & 14 & W24X370 & 50 & W24X68 \\
\hline 15 & W40X324 & 51 & W24X68 & 15 & W40X324 & 51 & W21X68 & 15 & W40X324 & 51 & W21X68 \\
\hline 16 & W36X280 & 52 & W24X76 & 16 & W27X281 & 52 & W21X83 & 16 & W27X307 & 52 & W21X83 \\
\hline 17 & W33X318 & 53 & W24X76 & 17 & W14X233 & 53 & W24X76 & 17 & W40X244 & 53 & W24X76 \\
\hline 18 & W33X291 & 54 & W30X116 & 18 & W33X241 & 54 & W21X83 & 18 & W33X241 & 54 & W21X83 \\
\hline 19 & W40X277 & 55 & W27X94 & 19 & W27X235 & 55 & W33X118 & 19 & W27X235 & 55 & W33X118 \\
\hline 20 & $\mathrm{~W} 24 \mathrm{X} 250$ & 56 & W21X83 & 20 & W36X300 & 56 & W24X84 & 20 & W36X300 & 56 & W24X84 \\
\hline 21 & W36X260 & 57 & W30X90 & 21 & W40X244 & 57 & W27X94 & 21 & W27X258 & 57 & W27X94 \\
\hline 22 & W33X291 & 58 & W44X198 & 22 & W14X211 & 58 & W30X90 & 22 & W14X211 & 58 & W30X90 \\
\hline 23 & W27X235 & 59 & W44X285 & 23 & W14X159 & 59 & W21X83 & 23 & W14X159 & 59 & W21X83 \\
\hline 24 & W12X170 & 60 & W24X68 & 24 & W14X159 & 60 & W21X83 & 24 & W14X159 & 60 & W21X83 \\
\hline 25 & W14X665 & 61 & W14X455 & 25 & W36X848 & 61 & W14X370 & 25 & W36X848 & 61 & W14X370 \\
\hline 26 & W36X798 & 62 & W14X398 & 26 & W36X848 & 62 & W14X398 & 26 & W36X848 & 62 & W14X398 \\
\hline 27 & W36X720 & 63 & W40X328 & 27 & W36X848 & 63 & W14X370 & 27 & W36X848 & 63 & W14X370 \\
\hline 28 & W33X619 & 64 & W14X233 & 28 & W36X848 & 64 & W14X193 & 28 & W36X848 & 64 & W14X193 \\
\hline 29 & W40X531 & 65 & W14X109 & 29 & W36X848 & 65 & W14X132 & 29 & W36X848 & 65 & W14X132 \\
\hline 30 & W36X439 & 66 & W12X72 & 30 & W36X848 & 66 & W14X90 & 30 & W36X848 & 66 & W14X90 \\
\hline 31 & W27X494 & 67 & W40X328 & 31 & W40X655 & 67 & W40X244 & 31 & W40X655 & 67 & W40X244 \\
\hline 32 & W33X619 & 68 & W14X283 & 32 & W27X407 & 68 & W14X233 & 32 & W27X407 & 68 & W14X233 \\
\hline 33 & W21X364 & 69 & W14X233 & 33 & W27X368 & 69 & W14X233 & 33 & W36X359 & 69 & W14X233 \\
\hline 34 & W40X297 & 70 & W40X192 & 34 & W30X357 & 70 & W33X221 & 34 & W36X328 & 70 & W33X221 \\
\hline 35 & W36X245 & 71 & W40X192 & 35 & W36X232 & 71 & W14X99 & 35 & W36X232 & 71 & W14X99 \\
\hline 36 & W14X283 & 72 & W14X132 & 36 & W27X129 & 72 & W14X90 & 36 & W27X129 & 72 & W14X90 \\
\hline $\begin{array}{l}\text { Weight, } \\
\text { kips (tons) }\end{array}$ & & $\begin{array}{c}5254.9 \\
(2383.6)\end{array}$ & & & $\begin{array}{l}482 \\
(218\end{array}$ & & & & $\begin{array}{l}4858 \\
(220\end{array}$ & & \\
\hline
\end{tabular}

\section{References}

[1] Saka, M. P. "Optimum Design of Steel Frames using Stochastic Search Techniques Based on Natural Phenomena: A Review", In: Topping, B. H. V. (ed.) Civil Engineering Computations: Tools and Techniques, Saxe-Coburg Publications, Stirlingshire, UK, 2007, pp. 105-147.

https://doi.org/10.4203/csets.16.6
[2] Saka, M. P. "Optimum design of steel frames with stability constraints", Computers \& Structures, 41(6), pp. 1365-1377, 1991. https://doi.org/10.1016/0045-7949(91)90274-P

[3] Erdal, F., Dogan, E., Saka, M. P. "An improved particle swarm optimizer for steel grillage systems", Structural Engineering and Mechanics, 47(4), pp. 513-530, 2013.

https://doi.org/10.12989/sem.2013.47.4.513 
[4] Kaveh, A., Talatahari, S. "Hybrid Algorithm of Harmony Search, Particle Swarm and Ant Colony for Structural Design Optimization", In: Geem, Z. W. (ed.) Harmony Search Algorithms for Structural Design Optimization, Springer, Berlin, Heidelberg, Germany, 2009, pp. 159-198.

https://doi.org/10.1007/978-3-642-03450-3_5

[5] Kaveh, A., Talatahari, S. "A Discrete Big Bang-Big Crunch Algorithm for Optimal Design of Skeletal Structures", Asian Journal of Civil Engineering, 11(1), pp. 103-122, 2010. [online] Available at: https://ajce.bhrc.ac.ir/Journal-Volumes-Issues/agentType/View/PropertyID/6120 [Accessed: 24 September 2019]

[6] Kaveh, A., Talatahari, S. "Optimum design of skeletal structures using imperialist competitive algorithm", Computers \& Structures, 88(21-22), pp. 1220-1229, 2010.

https://doi.org/10.1016/j.compstruc.2010.06.011

[7] Ozturk, H. T., Durmus, A. "Optimum cost design of RC columns using artificial bee colony algorithm", Structural Engineering and Mechanics, 45(5), pp. 643-654, 2013.

https://doi.org/10.12989/sem.2013.45.5.643

[8] Erdal, F. "The comparative analysis of optimal designed web expanded beams via improved harmony search method", Structural Engineering and Mechanics, 54(4), pp. 665-691, 2015.

https://doi.org/10.12989/sem.2015.54.4.665

[9] Gholizadeh, S., Gheyratmand, C., Davoudi, H. "Optimal design of double layer barrel vaults considering nonlinear behavior", Structural Engineering and Mechanics, 58(6), pp. 1109-1126, 2016. https://doi.org/10.12989/sem.2016.58.6.1109

[10] Tejani, G. G., Bhensdadia, V. H., Bureerat, S. "Examination of three meta-heuristic algorithms for optimal design of planar steel frames", Advances in Computational Design, 1(1), pp. 79-86, 2016. https://doi.org/10.12989/acd.2016.1.1.079

[11] Bhensdadia, V., Tejani, G. "Grey Wolf Optimizer (GWO) Algorithm for Minimum Weight Planer Frame Design Subjected to AISCLRFD", Advances in Intelligent Systems and Computing, 409, pp. 143-151, 2016.

https://doi.org/10.1007/978-981-10-0135-2_13

[12] Goldberg, D. E., Samtani, M. P. "Engineering Optimization Via Genetic Algorithm", In: Proceedings of the Ninth Conference on Electronic Computation, ASCE, New York, USA, 1986, pp. $471-482$.

[13] Kennedy, J., Eberhart, R. "Particle swarm optimization", In: Proceedings of ICNN'95-International Conference on Neural Networks, Perth, WA, Australia, 1995, pp. 1942-1948. https://doi.org/10.1109/ICNN.1995.488968

[14] Colorni, A., Dorigo, M., Maniezzo, V. "Distributed Optimization by Ant Colonies", In: Proceedings of the first European Conference on Artificial Life, Paris, France, 1991, pp. 134-142.

[15] Dorigo, M. "Optimization, learning and natural algorithms", $\mathrm{PhD}$ Thesis, Politecnico di Milano, 1992.

[16] Yang, X. S. "Nature-Inspired Metaheuristic Algorithms", Luniver Press, UK, 2008.

[17] Lamberti, L., Pappalettere, C. "Metaheuristic Design Optimization of Skeletal Structures: A Review", Computational Technology Reviews, 1, pp. 1-32, 2011.

https://doi.org/10.4203/ctr.4.1
[18] Koohestani, K., Kazemzadeh Azad, S. "An Adaptive Real-Coded Genetic Algorithm for Size and Shape Optimization of Truss Structures", In: Topping, B. H. V., Tsompanakis, Y. (eds.) Proceedings of the First International Conference on Soft Computing Technology in Civil, Structural and Environmental Engineering, Civil-Comp Press, Stirlingshire, UK, 2009, Paper 13.

https://doi.org/10.4203/ccp.92.13

[19] Tejani, G. G., Pholdee, N., Bureerat, S., Prayogo, D. "Multiobjective adaptive symbiotic organisms search for truss optimization problems", Knowledge-Based Systems, 161, pp. 398-414, 2018. https://doi.org/10.1016/j.knosys.2018.08.005

[20] Tejani, G. G., Pholdee, N., Bureerat, S., Prayogo, D., Gandomi, A. H. "Structural optimization using multi-objective modified adaptive symbiotic organisms search", Expert Systems with Applications, 125, pp. 425-441, 2019.

https://doi.org/10.1016/j.eswa.2019.01.068

[21] Hasançebi, O., Kazemzadeh Azad, S. "Adaptive dimensional search: A New metaheuristic algorithm for discrete truss sizing optimization", Computers \& Structures, 154, pp. 1-16, 2015. https://doi.org/10.1016/j.compstruc.2015.03.014

[22] AISC-ASD "Manual of steel construction-allowable stress design", 9th ed., American Institute of Steel Construction, Chicago, Illinois, USA, 1989.

[23] ANSI/AISC 360-05 "Specification for structural steel buildings", American Institute of Steel Construction, Chicago, Illinois, USA, 2005.

[24] Dumonteil, P. "Simple Equations for Effective Length Factors", Engineering Journal, American Institute of Steel Construction, 29, pp. 111-115, 1992.

[25] Hellesland, J. "Review and evaluation of effective length formulas", University of Oslo, Oslo, Norway, Rep. 94-2, 1994. [online] Available at: https://www.duo.uio.no/handle/10852/10381?locale-attribute $=$ en [Accessed: 25 September 2019]

[26] Schwefel, H. P. "Numerical optimization of computer models", John Wiley \& Sons, Chichester, UK, 1981.

[27] Erol, O. K., Eksin, I. "A new optimization method: Big Bang-Big Crunch", Advances in Engineering Software, 37(2), pp. 106-111, 2006.

https://doi.org/10.1016/j.advengsoft.2005.04.005

[28] Hasançebi, O., Çarbaş, S., Saka, M. P. "Improving the performance of simulated annealing in structural optimization", Structural and Multidisciplinary Optimization, 41(2), pp. 189-203, 2010. https://doi.org/10.1007/s00158-009-0418-9

[29] Hasançebi, O., Kazemzadeh Azad, S. "An exponential big bang-big crunch algorithm for discrete design optimization of steel frames", Computers \& Structures, 110-111, pp. 167-179, 2012. https://doi.org/10.1016/j.compstruc.2012.07.014

[30] ASCE 7-05 "Minimum design loads for buildings and other structures", American Society of Civil Engineers, Reston, VA, USA, 2005.

[31] Hasançebi, O., Çarbas, S., Dogan, E., Erdal, F., Saka, M. P. "Comparison of non-deterministic search techniques in the optimum design of real size steel frames", Computers \& Structures, 88(17-18), pp. 1033-1048, 2010.

https://doi.org/10.1016/j.compstruc.2010.06.006 
[32] Hasançebi, O., Erdal, F., Saka, M. P. "Adaptive Harmony Search Method for Structural Optimization", Journal of Structural Engineering, 136(4), pp. 419-431, 2010.

https://doi.org/10.1061/(ASCE)ST.1943-541X.0000128

[33] Hasançebi, O., Kazemzadeh Azad, S. "Improving Computational Efficiency of Bat-Inspired Algorithm in Optimal Structural Design", Advances in Structural Engineering, 18(7), pp. 1003-1015, 2015. https://doi.org/10.1260/1369-4332.18.7.1003
[34] Saka, M. P., Hasançebi, O. "Adaptive Harmony Search Algorithm for Design Code Optimization of Steel Structures", In: Geem, Z. W. (ed.) Harmony Search Algorithms for Structural Design Optimization, Studies in Computational Intelligence, Springer, Berlin, Heidelberg, Germany, 2009, pp. 79-120. https://doi.org/10.1007/978-3-642-03450-3_3 